\title{
Probiotics, Prebiotics, Synbiotics, and Paraprobiotics as a Therapeutic Alternative for Intestinal Mucositis
}

\begin{abstract}
Viviane Lima Batista', Tales Fernando da Silva', Luís Cláudio Lima de Jesus', Nina Dias Coelho-Rocha', Fernanda Alvarenga Lima Barroso', Laisa Macedo Tavares', Vasco Azevedo', Pamela Mancha-Agresti ${ }^{1,2 *}$ and Mariana Martins Drumond ${ }^{1,3 *}$

' Laboratório de Genética Celular e Molecular (LGCM), Departamento de Biologia Geral, Instituto de Ciências Biológicas, Universidade Federal de Minas Gerais (UFMG), Belo Horizonte, Brazil, ${ }^{2}$ Faculdade de Minas, FAMINAS-BH, Belo Horizonte, Brazil, ${ }^{3}$ Centro Federal de Educação Tecnológica de Minas Gerais (CEFET/MG), Departamento de Ciências Biológicas, Belo Horizonte, Brazil
\end{abstract}

OPEN ACCESS

Edited by:

Konstantinos Papadimitriou, University of Peloponnese, Greece

Reviewed by:

Natasa Golic

University of Belgrade, Serbia Eric Claassen,

Vrije Universiteit Amsterdam,

Netherlands

Jia Yin,

Hunan Normal University, China

${ }^{*}$ Correspondence:

Pamela Mancha-Agrest

p.mancha.agresti@gmail.com

Mariana Martins Drumond

mmdrumond@gmail.com

Specialty section:

This article was submitted to

Food Microbiology,

a section of the journal

Frontiers in Microbiology

Received: 21 March 2020

Accepted: 24 August 2020

Published: 17 September 2020

Citation:

Batista VL, da Silva TF,

de Jesus LCL, Coelho-Rocha ND, Barroso FAL, Tavares LM, Azevedo V, Mancha-Agresti $P$ and Drumond MM

(2020) Probiotics, Prebiotics,

Synbiotics, and Paraprobiotics as a Therapeutic Alternative for Intestinal

Mucositis.

Front. Microbiol. 11:544490.

doi: 10.3389/fmicb.2020.544490
Intestinal mucositis, a cytotoxic side effect of the antineoplastic drug 5-fluorouracil (5FU), is characterized by ulceration, inflammation, diarrhea, and intense abdominal pain, making it an important issue for clinical medicine. Given the seriousness of the problem, therapeutic alternatives have been sought as a means to ameliorate, prevent, and treat this condition. Among the alternatives available to address this side effect of treatment with 5-FU, the most promising has been the use of probiotics, prebiotics, synbiotics, and paraprobiotics. This review addresses the administration of these "biotics" as a therapeutic alternative for intestinal mucositis caused by 5 -FU. It describes the effects and benefits related to their use as well as their potential for patient care.

Keywords: lactic acid bacteria, chemotherapy, intestinal inflammation, treatment, mucosite

\section{INTRODUCTION}

Cancer is a disease characterized by uncontrolled proliferation of cells with cellular differentiation properties, having the capacity to invade tissues and organs and spread to other regions of the body, causing metastases (World Health Organization [WHO], 2018). This disease is the second leading cause of death globally, according to the World Health Organization, accounting for an estimated 9.6 million deaths in 2018; lung ( 1.76 million deaths), colorectal (862,000 deaths), stomach (783,000 deaths), liver (782,000 deaths), and breast cancer (627,000 deaths) are the most common types and have the highest mortality rates (World Health Organization [WHO], 2018).

Despite the high incidence and mortality rates, when identified early, cancer is a potentially curable and treatable disease. Treatment may be done through surgery, chemotherapy, radiotherapy, or bone marrow transplantation, depending on the type of cancer, degree of tumor aggressiveness, as well as the patient's physical and immunological status. It is often necessary to combine more than one type of treatment to achieve satisfactory results (World Health Organization [WHO], 2018).

Antineoplastic chemotherapy consists of the use of drugs that destroy cancer cells, inhibit their growth, and prevent their spread by targeting DNA or critical processes involved in cell division (Guichard et al., 2017; Shields, 2017). The traditional chemotherapeutics are classified according to their mechanisms of action, including antimetabolites, microtubule-targeting agents, topoisomerases, and antibiotics (Shields, 2017). The therapeutic arsenal mostly used in the 
treatment of neoplasms include oxaliplatin, irinotecan, capecitabine, cisplatin, methotrexate, 5-fluorouracil (5-FU), and FOLFIRI (an association of 5-fluorouracil, irinotecan, and leucovorin), among others (Nussbaumer et al., 2011; Cassidy and Syed, 2017; Guichard et al., 2017).

The medication 5-FU is highlighted among the chemotherapeutic alternatives and has been mainly used in the treatment of advanced types of cancer, such as colorectal cancer, as well as malignant head and neck cancer, breast, stomach, and some skin cancers (Longley et al., 2003; Martins and Wagner, 2013; Cassidy and Syed, 2017; Guichard et al., 2017). This drug is an analog of uracil and thymine (Figure 1), which is metabolized in the liver, producing many metabolites. One of them binds to and inhibits the enzyme thymidylate synthase and, consequently, ends up interfering with DNA synthesis and cell division (see the Mechanism of Action of 5-FU section). On the other hand, this drug can act by the incorporation of its metabolites into the DNA and/or RNA of these cells (Sonis, 2004), which impedes their normal functioning and induces apoptosis (Longley et al., 2003; Miura et al., 2010).

However, 5-FU's non-specific mechanism of action results in side effects such as nausea, cardiotoxicity, leukopenia, alopecia, myelosuppression, diarrhea, and oral and intestinal mucositis (Duncan and Grant, 2003; Soveri et al., 2014; Thomas et al., 2016; Cinausero et al., 2017). Intestinal mucositis is the most prevalent side effect of 5-FU therapy (50-80\% of reported cases) and one of the main limiting factors for continuing treatment (Kim et al., 2015).

Mucositis is an inflammation of the gastrointestinal tract (GIT), with symptoms that include diarrhea, abdominal pain, bleeding, fatigue, malnutrition, electrolyte imbalance, and infections, causing complications that may be life threatening (Sonis, 2004; Touchefeu et al., 2014; Kim S. et al., 2018). The cytotoxic effects of 5-FU in the GIT cells are a severe problem for oncological therapeutics, as they decrease the patient's ability to tolerate treatment, affecting the quality of life, directly influencing the success of therapy (Jamali et al., 2018).

Within this context, therapeutic alternatives have been sought as a means to prevent or ameliorate intestinal mucositis. Among these alternatives, the most promising are the use of probiotics ["live microorganisms which when administered in adequate amounts confer a health benefit on the host" (FAO/WHO, 2001)], prebiotics ["a substrate that is selectively utilized by host microorganisms conferring a health benefit" (Gibson et al., 2017)], synbiotics ["a mixture of probiotics and implantation of live microbial dietary supplements in the GIT, by selectively stimulating the growth and/or activating the metabolism of one or a limited number of health-promoting bacteria, and thus improving host welfare" (Gibson and Roberfroid, 1995)], paraprobiotics, and postbiotics, which can be defined as non-viable microorganisms, cell fractions or cell metabolites, bacteriocins, organic acids, and enzymes (Rad et al., 2020).

In this review, we address the evidence for the suitability of probiotics, prebiotics, synbiotics, and paraprobiotics as a therapeutic alternative for intestinal mucositis caused by the antineoplastic drug 5-FU.

\section{MECHANISM OF ACTION OF 5-FU}

The drug 5-FU is an antimetabolite analogous to uracil, which differs by the substitution of a hydrogen atom with fluorine at the fifth position of the uracil molecule. Developed in the 1950s and introduced in cancer therapy to inhibit cell division and proliferation of cancer cells, this substance is among the class of antineoplastic drugs with a vast spectrum of action in oncological practice, being widely used for the treatment of a variety of tumors (Thomas et al., 2016; Kato et al., 2017).

To control the abnormal proliferation of cancer cells, 5FU enters into the cells through facilitated transport, which is the same mechanism involved in its intracellular conversion into active metabolites [fluorodeoxyuridine monophosphate (FdUMP), fluorodeoxyuridine triphosphate (FdUTP), and 5fluorouridine triphosphate (FUTP)]. These metabolites may exhibit three different mechanisms of action: (1) FdUMP inhibits the activity of the enzyme thymidylate synthase causing an imbalance in the pool of nucleotides, consequently decreasing the concentration of the deoxynucleotides dTTP and dATP, essential for DNA repair; (2) FdUTP binds to the DNA structure, inhibiting its synthesis, blocking cell division; and (3) FUTP can be incorporated into RNA, damaging it, leading to functional loss and cell death (Longley et al., 2003; Zhang et al., 2008; Miura et al., 2010; Figure 2).

Clinical evidence of patients undergoing oncologic therapy with 5-FU shows that the effects of this chemotherapy vary among users. From 20 to $40 \%$ of the patients treated with the standard dose of this drug (10-15 mg/kg body weight, for 34 days intravenously) develop some degree of mucositis, and about $80-100 \%$ of the patients treated with high doses (350$500 \mathrm{mg} / \mathrm{kg}$ body weight) develop GIT problems (Crombie and Longo, 2016; Cinausero et al., 2017).

\section{EFFECTS OF 5-FU ON THE GASTROINTESTINAL TRACT}

In addition to having a digestive and nutrient absorption role, the GIT mucosa acts as a physical and immunological barrier, having the ability to defend the body against potentially harmful agents that can trigger inflammatory responses in the intestine (Salvo Romero et al., 2015; König et al., 2016). The intestinal barrier is categorized according to the various levels of protection, as well as the location and nature of its cellular and extracellular components (Vancamelbeke and Vermeire, 2017). These include mainly the mucus layer associated with the commensal microbiota of the gut, antimicrobial peptide and immunoglobulin A ( IgA) secretion, the monolayer of specialized epithelial cells (enterocytes, Paneth cells, goblet cells, stem cells, and enteroendocrine cells), and the lamina propria, a specialized connective tissue in which innate and adaptive immune cells reside, such as $\mathrm{T}$ cells, B cells, dendritic cells (DCs), macrophages, neutrophils, eosinophils, and the newly discovered innate lymphoid cells (ILCs) (Vancamelbeke and Vermeire, 2017). 
<smiles>O=c1[nH]cc(F)c(=O)[nH]1</smiles>

5-fluorouracile<smiles></smiles>

uracil<smiles>Cc1c[nH]c(=O)[nH]c1=O</smiles>

thymine
FIGURE 1 | Chemical structure of 5-fluorouracil (5-FU) and its analogs uracil and thymine. All three structures differ in the radical present at the structure's fifth position.

Although the intestinal barrier plays an essential role in the body's homeostasis, it is susceptible to 5-FU oncologic therapy ( $\mathrm{Yu}, 2013)$. The intestinal mucositis caused by 5 -FU mainly affects the small intestine (duodenum, jejunum, and ileum), characterized by inflammation, loss of intestinal structure and functionality, villous atrophy, goblet and Paneth cell degeneration, reduction in mucin secretion, increased intestinal permeability, cell death, polymorphonuclear cell infiltration, and increased production of proinflammatory cytokines, such as interleukin-1 $\beta$ (IL-1 $\beta$ ), IL-6, and tumor necrosis factor- $\alpha$ (TNF- $\alpha$ ), mucosal tissue exposed to infection, and alteration of the intestinal microbiota composition (Chang et al., 2012; Lee, 2014).

The pathology of mucositis can be divided into five phases (initiation, response to primary damage, signal amplification, ulceration, and healing) (Sonis, 2004; Figure 3). The initiation phase occurs when the intestinal mucosa is exposed to 5FU, which promotes DNA/RNA damage, either because it binds directly to these biomolecules or through the oxidative stress caused by reactive oxygen species (ROS) production. These factors induce tissue damage (Sonis, 2004; Villa and Sonis, 2015; Cereda et al., 2018), which activates several signal transduction pathways, such as nuclear factor $\kappa \mathrm{B}$ (NF$\kappa \beta$ ) pathway signaling. This situation leads to the induction of various inflammatory mediators, such as IL-8, TNF- $\alpha$, cyclooxygenase- 2 enzyme (COX-2), IL-6, and IL-1 $\beta$, among others, that are responsible for mucosal toxicity (Sonis, 2004; Cinausero et al., 2017).

The recruitment of these proinflammatory cytokines acts indirectly on signal amplification (amplification phase) via a positive feedback mechanism, activating pathways that increase

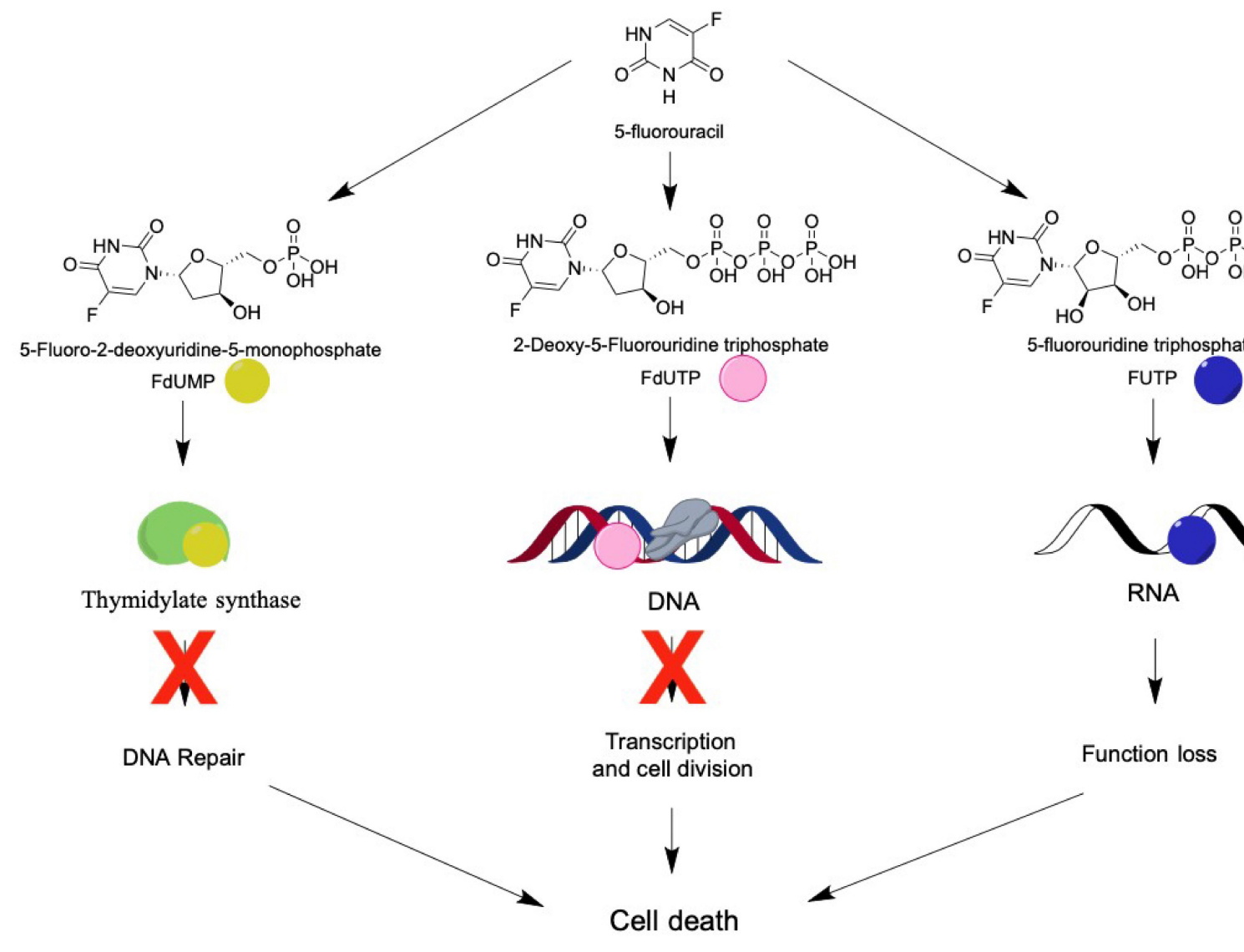

FIGURE 2 | 5-FU's metabolites and their molecular targets. 5-FU is intracellularly metabolized into fluorodeoxyuridine monophosphate (FdUMP), which binds to the enzyme thymidylate synthetase, resulting in decreased production of dTTP and dATP and blocking cell repair; or into fluorodeoxyuridine triphosphate (FdUTP) and binds to the DNA, inhibiting duplication and transcription; or into 5-fluorouridine triphosphate (FUTP) and binds to RNA, leading to a loss of function. All three metabolites cause damage to the cell on a genomic level, culminating in cell death. 


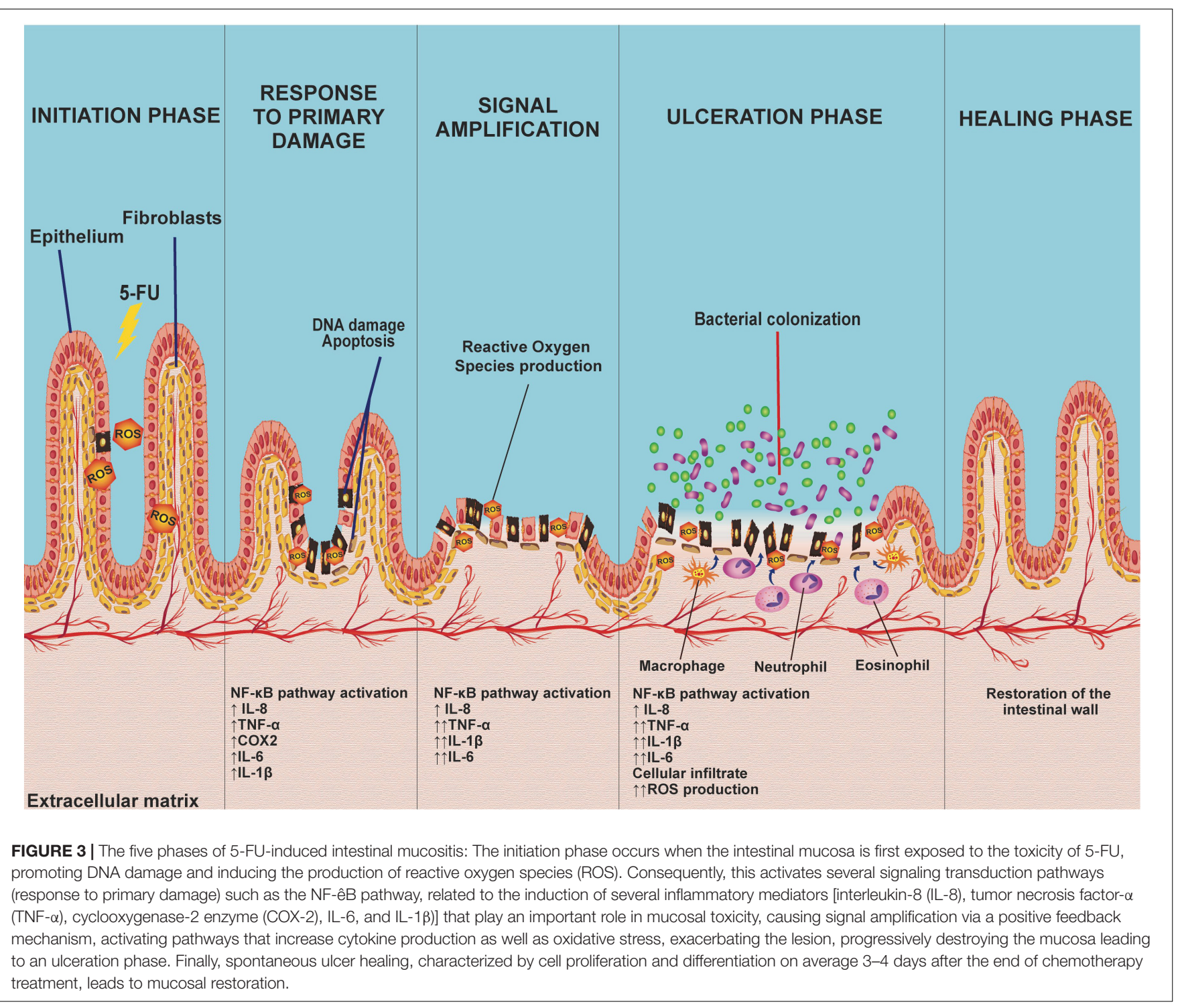

proinflammatory cytokine production (TNF- $\alpha$, IL-1 $\beta$, and IL-6), as well as oxidative stress. The increase in the production of these factors initiates a cascade of reactions that leads to the activation of matrix metalloproteinases, resulting in tissue damage or an increase in TNF- $\alpha$ production, exacerbating the initial lesion (Sonis, 2004).

The progressive destruction of the mucosa culminates in an ulceration phase, which occurs when loss of integrity and function of the epithelium occurs. At this stage, there are symptomatic lesions that, apart from being prone to pathogenic bacterial colonization, stimulate the activation and infiltration of defense cells, including macrophages, neutrophils, and eosinophils, in the intestinal mucosa. These cells increase the production of oxidant compounds, resulting in an increase in the depth of intestinal ulcers, consequently increasing bacterial translocation (Villa and Sonis, 2015; Cinausero et al., 2017; Cereda et al., 2018).

Finally, the healing phase is characterized by cell proliferation and differentiation. This phase occurs, on average, 3-4 days after the last chemotherapy treatment, leading to restoration of the mucosa (Sonis, 2004; Villa and Sonis, 2015).

\section{EFFECTS OF 5-FU ON INTESTINAL MICROBIOTA}

In addition to causing structural damage to the intestinal epithelium, the mucositis caused by chemotherapeutic agents has a crucial influence on the intestinal microbiota (van Vliet et al., 2010). The GIT has a complex ecological population, constituted by more than a thousand different species of microorganisms, though their distribution varies along the GIT (Mowat and Agace, 2014; Rajilić-Stojanović and de Vos, 2014); low concentrations and bacterial diversity (up to $10^{3} \mathrm{CFU} / \mathrm{ml}$ ) are found in the upper GIT (stomach, duodenum, jejunum, and proximal ileum) (Walter and Ley, 2011). A larger number of bacteria $\left(10^{9}-10^{12} \mathrm{CFU} / \mathrm{ml}\right)$ reside 
in the lower compartments of the GIT (distal ileum and colon), which constitutes, to date, the habitat with the highest known microbial density (Mowat and Agace, 2014; Jandhyala et al., 2015; Thursby and Juge, 2017). Due to the low oxygen tension in the colon, the most prevalent bacterial groups consist of anaerobic species, such a Clostridia, Enterobacteria, Enterococcus, Bacteroides, Bifidobacteria, Fusobacteria, Lactobacilli, Peptococci, Peptostreptococci, Prevotellaceae, Roseburia, Ruminococci, and Verrucomicrobia (Simon and Gorbach, 1982; Bäckhed et al., 2005; Mowat and Agace, 2014).

The intestinal microbiota acts through several mechanisms to maintain the homeostasis of the organism, living in mutuality with the host, benefiting from the nutrient-rich environment offered by the organism and, in exchange, performing innumerable beneficial functions, including elimination of pathogens, production of vitamins and short-chain fatty acids (SCFA), as well as modulation of the enteric and systemic immune systems (Lane et al., 2017; Thursby and Juge, 2017). However, when this mutualism becomes unbalanced, the intestinal microbiota can contribute to the onset of infectious diseases, chronic inflammation, and autoimmune diseases (de Oliveira et al., 2017).

The commensal microbiota, such as Bifidobacterium infantis and Bacteroides thetaiotaomicron, have been shown to decrease NF- $\kappa \mathrm{B}$ activation, decreasing levels of endotoxins and of plasma proinflammatory cytokines (Stringer et al., 2009). Studies have demonstrated that treatment with 5-FU alters the relative abundance of several genera of the intestinal microbiota, such as Clostridium, Lactobacillus, Enterococcus, Bacteroides, Staphylococcus, Streptococcus, and Escherichia (Stringer et al., 2009). Thus, disrupted homeostasis of the intestinal microbiota can affect the mucosal immune system due to an imbalance between the production of pro- and antiinflammatory mediators, resulting in intestinal inflammation (Autenrieth and Baumgart, 2017; Holleran et al., 2017).

Given the possibility that intestinal mucositis is closely related to intestinal microbiota dysbiosis (von Bültzingslöwen et al., 2003; Yu, 2018), probiotic microorganisms have been presented as an alternative treatment due to their beneficial properties in the GIT. Given these characteristics, several studies have shown that probiotics can be an effective therapeutic alternative for the reduction of antineoplastic-induced intestinal mucositis.

\section{PROBIOTICS}

In order, to be considered a probiotic and be able to exert health benefits for the host, microorganisms must have some specific attributes, such as being capable of remaining viable during transport and storage, and tolerating the low $\mathrm{pH}$ of the gastric lumen and the action of bile, and pancreatic and intestinal secretions. Many probiotics are able to colonize the GIT and stimulate the immune system (Wang M. et al., 2016; Mokoena, 2017). Furthermore, resistance to antibiotics in probiotic strains should be analyzed in order to assess their safety, as well as the level and the source of this resistance (Zhang et al., 2018). Intrinsic resistance is unlikely to spread horizontally between bacteria (Mathur and Singh, 2005), while acquired resistance could be transferred to other organisms, including pathogens, representing a potential risk to the health of the host (van Reenen and Dicks, 2011). The most well-studied and characterized probiotics belong to the lactic acid bacteria (LAB) group. However, other microorganisms also present probiotic properties, such as some Saccharomyces spp., and bacteria of the genera Bifidobacterium and Faecalibacterium (Pot et al., 2013; Bastos et al., 2016; Chang et al., 2019).

LAB mainly include the genera Lactobacillus, Leuconostoc, Lactococcus, Pediococcus, and Streptococcus, among others, and constitute a group of Gram-positive microorganisms, anaerobic or aerotolerant, non-spore forming, resistant to low $\mathrm{pH}$, and able to produce lactic acid as the final product of the fermentation of carbohydrates (Wang Y. et al., 2016; Mokoena, 2017; Plavec and Berlec, 2019). Furthermore, these bacteria have been used for a long time in several industrial processes for the production of fermented foods, such as cheese, yogurts, etc. (Soccol et al., 2010), and they frequently present probiotic properties. Additionally, these organisms have been explored for protein heterology production and as live delivery systems for gene and biotherapeutic vaccines, with potential applications for the treatment and prevention of various pathological conditions, in both human and veterinary medicine (Carvalho et al., 2017; Gomes-Santos et al., 2017; LeCureux and Dean, 2018; Kuczkowska et al., 2019).

\section{MECHANISMS OF ACTION OF PROBIOTICS}

Studies have shown that benefits for human health are attributed to consumption of probiotics, mainly for GIT diseases (Fedorak et al., 2015; Acurcio et al., 2017), though also for other diseases, including osteoporosis (Collins et al., 2018), cancer (Zaharuddin et al., 2019), obesity and type 2 diabetes (SaezLara et al., 2015; Wang et al., 2017; Hsieh et al., 2018), depression (Wallace et al., 2020), and atopic dermatitis (Rather et al., 2016). In this context, the main mechanisms of action described for these microorganisms in the host include: (i) colonization and regulation of a dysbiotic intestinal microbiota (Shi et al., 2017); (ii) protection of the epithelial barrier by maintaining tight junction integrity (Blackwood et al., 2017); (iii) induction of mucin production (Aliakbarpour et al., 2012) and B-cell-secreting IgA, which are important defense mechanisms necessary to maintain epithelial integrity and to protect the intestine from the external environment; (iv) increasing adherence to the intestinal mucosa and inhibiting of concomitant pathogen adherence based on competition for available nutrients and sites of mucosal adhesion (Collado et al., 2010; MonteagudoMera et al., 2019); (v) competitive exclusion of pathogenic microorganisms, such as Staphylococcus aureus and Salmonella typhimurium (Halder et al., 2017; Plaza-Díaz et al., 2017); (vi) production of antimicrobial substances such as acetic and lactic acids, and bacteriocins, which have strong inhibitory effects against Gram-negative bacteria and have been considered as the main antimicrobial compounds produced by probiotics against pathogens (Alakomi et al., 2000; De Keersmaecker et al., 2006; Makras et al., 2006; Bermudez-Brito et al., 2012; Mokoena, 2017; 
Gaspar et al., 2018; Castilho et al., 2019); (vii) production and secretion of metabolites of SCFAs with anti-inflammatory properties, such as acetate, propionate, and butyrate, which exert beneficial effects on intestinal and immune cells, being important compounds for cell proliferation, cell differentiation, and gene expression, and they are signaling molecules of immunological pathways; butyrate is the primary energy source of colonocytes, and it has an epithelial barrier function; SCFAs can also induce expression of the anti-inflammatory cytokine IL-10, inhibiting inflammatory responses (Parada Venegas et al., 2019); (viii) inhibition of the activation of the NF- $\kappa \mathrm{B}$ signaling pathway (Kaci et al., 2011; Gao et al., 2015); (ix) interaction with the gut-brain axis via the production of metabolites such as $\gamma$-aminobutyric acid (GABA) (Kim N. et al., 2018); and (x) modulation of the host's innate and/or adaptive immune system responses through interaction with epithelial cells, dendritic cells, monocytes, macrophages, and lymphocytes (Azad et al., 2018).
In addition, probiotics can act by inducing host autophagy to attenuate oxidative stress-induced intestine injury (Wu et al., 2019; Figure 4).

Thus, due to the numerous possible pathways in which probiotics could be involved, their study as therapeutics of various diseases, especially those related to the GIT, is of particular importance.

\section{EFFECTS OF PROBIOTICS ON INTESTINAL MUCOSITIS}

The proposed mechanisms of action for the beneficial effects of probiotic microorganisms in diseases affecting the GIT are diverse, heterogeneous, strain specific, and depend on the quantity of probiotics used (Plaza-Díaz et al., 2017). Since the immunomodulatory and anti-inflammatory effects

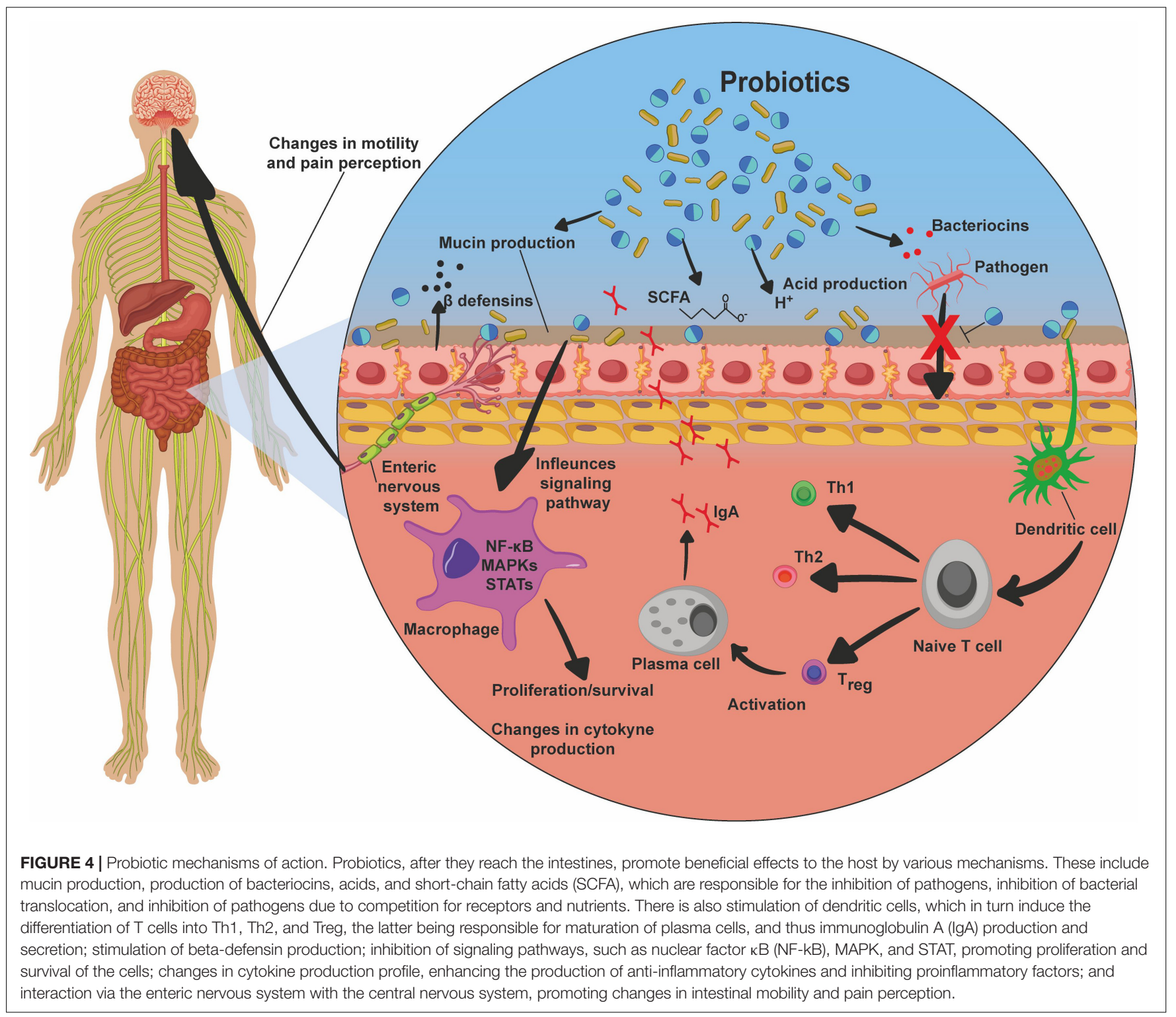


reported for $\mathrm{LAB}$, as well as other probiotics, are strain dependent, it is necessary to identify and characterize species and strains with probiotic potential and investigate their effects on different targets or diseases (Plaza-Díaz et al., 2017). Table 1 presents the main findings for the effects of probiotics on intestinal mucositis.

In this context, studies conducted in vitro using Caco2 cells (Fang et al., 2014) and in vivo with rats and mice

TABLE 1 | Effects of probiotics, prebiotics, synbiotics, and paraprobiotics in intestinal mucositis.

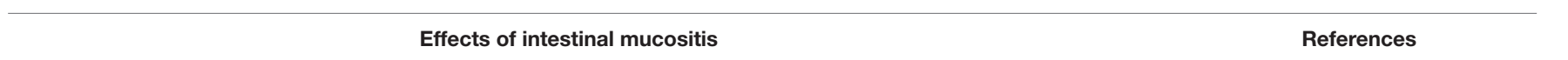

\section{Probiotics strain}

Lactobacillus acidophilus

Lactobacillus acidophilus A4

Lactobacillus casei variety rhamnosus (Lcr35)

Bifidobacterium bifidum G9-1

Bifidobacterium infantis

Association: (B. breve, L. acidophilus, L. casei, and Streptococcus thermophilus)

Association: (L. acidophilus, L. paracasei, L. rhamnosus, and B. lactis)

Association: Whey protein isolate, to skim milk fermented by $L$. casei and Propionibacterium freudenteichii Lactobacillus delbrueckii subsp. lactis CIDCA 133

Saccharomyces boulardii

\section{Prebiotics}

Fructooligosaccharide (FOS)

\section{Synbiotics}

Simbioflora ${ }^{\circledR}$

\section{Paraprobiotics}

L. rhamnosus inactivated by heat
Inhibited nuclear factor $\kappa \mathrm{B}(\mathrm{NF}-\kappa \beta)(\mathrm{NF}-\kappa \mathrm{B})$ pathway signaling

Regulated levels of the proinflammatory cytokines [tumor necrosis factor- $\alpha$ (TNF- $\alpha)$, interleukin-1 $\beta$ (IL-1 $\beta$ ), and the C-X-C motif chemokine ligand (CXCL)]

Reversed gastrointestinal dysmotility, increased gastric emptying and intestinal transit

Stimulated the overexpression of mucin genes (MUC2 and MUC5AC)

Reduced myeloperoxidase (MPO) activity

Reduced expression of proinflammatory cytokine IL-1 $\beta$

Reduced production of proinflammatory cytokines (TNF- $\alpha, \mathrm{IL}-1 \beta$, IFN- $\gamma, \mathrm{IL}-10$, and IL-6).

Attenuated the loss of goblet cells, decreased Firmicutes and increased Bacteroidetes

Reduced the frequency of diarrhea

Restored villus/crypt ratio

Attenuated histopathological alteration, with decrease cell infiltrate in crypts

Regulated intestinal microbiota (decrease Firmicutes and increase Bacteroidetes abundance)

Reduced the concentrations of proinflammatory cytokines TNF- $\alpha$ and IL-1 $\beta$ and MPO activity

Reduced diarrhea and interrupt weight loss

Improved the histologic parameters, ameliorating mucosal damage

Reduced Th1 and Th17 cells, and increased CD4 + CD25 + Foxp3 + Tregs response

Reduced neutrophil infiltration, proinflammatory cytokines (TNF- $\alpha, I L-4$, and IL-6), and intestinal permeability

Restored of the intestinal epithelium architecture

Prevented epithelial injury in intestinal mucositis, with an increase in the villus/crypt ratio Reduced the malondialdehyde (MDA), MPO, TNF- $\alpha$, and IL-6 levels Increased glutathione (GHS) levels in the duodenum and jejunum sections

Ameliorated histological scores and prevented villus shortening

Reduced weight loss and degeneration of goblet cells

Prevented body mass loss

Inhibited length reduction of the intestine caused by 5-fluorouracil (5-FU)

Restored histopathological damage

Reduced inflammatory parameters: neutrophil, eosinophil, leukocyte infiltrate reduction, and immunoglobulin A $(\lg A)$ secretion

Reduced intestinal permeability

Reduced cells apoptosis and inflammatory factors (nitrite concentration, neutrophil infiltrate

TNF- $\alpha$, IL-1 $\beta$ cytokines, and CXCL-1 chemokine)

Improved the intestinal functions such as gastric emptying, gastrointestinal transit, absorption, and intestinal permeability

Modulated the expression of TLR2, TLR4, MyD88, NF-кB extracellular signal, regulated

kinase 1/2 (ERK1/2), phospho-p38 MAPK, phospho-c-Jun N-terminal kinase (phospo-JNK) in jejunum/ileum and in $\mathrm{Caco} 2$ cells

Reduced MPO activity in jejunum section

Decreased inflammatory infiltrate and preserved intestinal epithelium

Smith et al., 2008;

Attenuated weight loss and increased catalase levels

Attenuated weight loss

Improved histology of the intestinal mucosa and preserved epithelial architecture

Reduced eosinophil infiltrate

Decreased intestinal permeability

Increased the production of extracellular factors, such as SCFA (acetate and butyrate)

Prevented the expression of monocyte chemoattractant protein 1 (MPC-1)

Fang et al., 2014
Galdino et al., 2018

Justino et al., 2015

Oh et al., 2017

Yeung et al., 2015;

Chang et al., 2018

Kato et al., 2017

Mi et al., 2017

Tang et al., 2017

Quaresma et al., 2019

Cordeiro et al., 2018

De Jesus et al., 2019

Justino et al., 2015, 2020

Trindade et al., 2018 
have demonstrated strain-dependent effects of probiotics for the prevention/treatment of experimental mucositis induced by $5-\mathrm{FU}$, proving to be an effective therapeutic alternative for the treatment of this disease. Thus, they could be used in parallel with chemotherapy to promote the attenuation of gastrointestinal toxicity caused by cancer drugs, which is promising for improving the quality of life of patients undergoing chemotherapy treatment (Mi et al., 2017; Chang et al., 2018).

Lactobacillus acidophilus can decrease intestinal damage caused by 5 -FU (applied at a dose of $450 \mathrm{mg} / \mathrm{kg}$ ) by inhibiting the signaling of the NF- $\mathrm{B}$ pathway, reducing levels of proinflammatory cytokines, such as TNF- $\alpha$, IL- $1 \beta$, and the $\mathrm{C}-\mathrm{X}-\mathrm{C}$ motif chemokine ligand 1 (CXCL-1); reversion in gastrointestinal dysmotility and increased gastric emptying and intestinal transit were observed (Justino et al., 2015). This probiotic was able to reduce inflammation and normalize bowel function in mice (Justino et al., 2015). Additionally, Oh et al. (2017) demonstrated that L. acidophilus A4 decreased the severity of intestinal mucositis induced by 5 -FU $(150 \mathrm{mg} / \mathrm{kg})$ by stimulating overexpression of mucin genes (MUC2 and MUC5AC), reducing myeloperoxidase (MPO) activity, and inhibiting expression of proinflammatory cytokines, such as IL$1 \beta$, in mice (Oh et al., 2017).

Lactobacillus casei variety rhamnosus (Lcr35, Antibiophilus ${ }^{\circledR}$, France) reduced the production of proinflammatory cytokines (TNF- $\alpha$, IL-1 $\beta$, IFN- $\gamma$, and IL-6), attenuated the loss of goblet cells, reduced the frequency of diarrhea, and restored the villus/crypt ratio, demonstrating an anti-inflammatory effect on tissue damage caused in the intestinal mucosa by administering 5 -FU (30 mg/kg) for 5 days (Yeung et al., 2015). The protective effect of Lcr35 $\left(1 \times 10^{7} \mathrm{CFU}\right)$ was also demonstrated in a colorectal cancer model; Balb/c mice were treated with a chemotherapeutic association called FOLFOX $(30 \mathrm{mg} / \mathrm{kg}$ of 5 FU; $10 \mathrm{mg} / \mathrm{kg}$ of leucovorin, and $1 \mathrm{mg} / \mathrm{kg}$ of oxaliplatin) during 5 days (Chang et al., 2018). Lcr35 treatment was able to attenuate intestinal mucosa damage through regulation of the expression of proinflammatory cytokines (IL- $1 \beta$, IL-6, TNF- $\alpha$, and IL10) induced by FOLFOX in the jejunum segment and also affected the gut microbiota composition, decreasing Firmicutes and increasing Bacteroidetes abundance (Chang et al., 2018). Thus, Lcr35 is a promising therapeutic strategy for the prevention or management of chemotherapy-induced intestinal mucositis (Chang et al., 2018).

A component in the intestinal microbiota, Bifidobacterium bifidum G9-1 (BBG9-1), has been widely used as a treatment for diarrhea and constipation, as well as for intestinal mucositis induced by 5 -FU (50 mg/kg/6 days) (Kato et al., 2017). This probiotic can reduce diarrhea and interrupt weight loss, as well as being able to attenuate villus shortening and goblet cell degeneration. It can decrease inflammatory infiltrate in crypt cells, reduce MPO activity, reduce TNF- $\alpha$ and IL-1 $\beta$ levels, and also regulate the intestinal microbiota (decrease Firmicutes and increase Bacteroidetes abundance), demonstrating its ability to reduce the severity of 5-FU-induced intestinal mucositis (Kato et al., 2017).

$\mathrm{Mi}$ et al. (2017) demonstrated that B. infantis $\left(1 \times 10^{9} \mathrm{CFU} / 11\right.$ days $)$ administration, in a synergic colorectal cancer treatment model with 5 -FU (75 mg/kg/3 days) and oxaliplatin $(8 \mathrm{mg} / \mathrm{kg} / 3$ days $)$, was able to reduce the deleterious effects to the intestinal mucosa induced by chemotherapy. This probiotic improved the histology parameters, ameliorating the mucosal damage by decreasing Th1 and Th17 cells, and increasing the $\mathrm{CD}^{+}{ }^{+} \mathrm{CD} 25^{+}$Foxp $^{+}$Tregs response (Mi et al., 2017).

A combination of probiotic strains also demonstrated effectiveness in the reduction of intestinal damage induced by 5 -FU chemotherapy. DM\#1 mixture (B. breve DM8310, L. acidophilus DM8302, L. casei DM8121, and Streptococcus thermophillus DM8309) administration improved the restoration of the epithelial architecture, reduced neutrophil infiltration, reduced proinflammatory cytokines (TNF- $\alpha$, IL-4, IL-6), and decreased intestinal permeability in mice treated with 5-FU (30 mg/kg/5 days) (Tang et al., 2017). Another study using a probiotic mix (L. acidophilus, L. paracasei, L rhamnosus, and $B$. lactis) showed that the mixture was able to prevent epithelial injury in intestinal mucositis induced by $5-\mathrm{FU}(450 \mathrm{mg} / \mathrm{kg})$, with an increase in the villus/crypt ratio and reduced malondialdehyde (MDA), MPO, TNF- $\alpha$, and IL-6 levels in all small intestinal segments (duodenum, jejunum, and ileum) (Quaresma et al., 2019). In addition, administration of the probiotic mix resulted in an increase in glutathione (GSH) levels in the duodenum and jejunum sections and attenuated the delay in gastric emptying (Quaresma et al., 2019).

The therapeutic effects of probiotics also have been demonstrated for fermented products, which can be consumed by cancer patients. Milk fermented by Lactobacillus delbrueckii CIDCA $133\left(7.5 \times 10^{7} \mathrm{CFU}\right)$ attenuated the damage caused to the intestinal mucosa by 5 -FU $(300 \mathrm{mg} / \mathrm{kg})$, both in the recovery of the architecture of the epithelium, including prevention of goblet cell degeneration, and reduction of the polymorphonuclear cell infiltrate, with reduced IgA secretion and intestinal permeability (De Jesus et al., 2019).

A mulberry leaf extract fermented by L. acidophilus A4 strain stimulated overexpression of mucin genes (MUC2 and MUC5AC), promoted reduction of MPO, inhibited expression of proinflammatory cytokines, such as IL-1 $\beta$, and reduced the loss of intestinal barrier function generated by 5 -FU (150 mg/kg) administration (Oh et al., 2017).

The role of whey protein isolate (WPI) added to skim milk fermented by Lactobacillus casei BL23 (L. casei BL23) or by Propionibacterium freudenreichii CIRM-BIA138 (P. freudenreichii 138) was studied in a 5-FU-induced mucositis mouse model (Cordeiro et al., 2018). Milk fermented by both bacteria was sufficient to reduce weight loss, reduce histological scores, and prevent villus shortening and degeneration of goblet cells. WPI addition to fermented milk improved the effects of these probiotics, compared to when they were administrated alone (Cordeiro et al., 2018).

In addition to bacteria, yeasts can also have a beneficial effect on gastrointestinal mucositis. In this context, Porto et al. (2019) showed the effect of Saccharomyces cerevisiae UFMG A-905 alone or after enrichment with selenium, for intestinal mucositis treatment. This probiotic composition was able to preserve intestinal architecture and reduce nitrite concentration, 
lipid peroxidation, intestinal permeability, and inflammatory parameters, protecting mice against pathological consequences caused by 5-FU administration (Porto et al., 2019).

The probiotic, thermophilic, non-pathogenic yeast, Saccharomyces boulardii, was also tested for intestinal mucositis treatment; the histopathological changes caused by 5 -FU were significantly reduced, including cell apoptosis and inflammatory parameters (nitrite concentration, neutrophil infiltrate, TNF- $\alpha$ and IL-1 $\beta$ cytokines, and CXCL-1 chemokine). This probiotic organism also improved the intestinal functions, such as gastric emptying, gastrointestinal transit, absorption, and intestinal permeability (Justino et al., 2015).

The effects of $S$. boulardii were evaluated by in vitro (Caco2 cells treated with $1 \mathrm{mM} \mathrm{5-FU/24} \mathrm{h)} \mathrm{and} \mathrm{in} \mathrm{vivo} \mathrm{assays}$ [Swiss mice treated with S. boulardii $\left(1 \times 10^{9} \mathrm{CFU} / \mathrm{kg} / 3\right.$ days $)$, mucositis induction by 5 -FU (450 mg/kg)] (Justino et al., 2020). S. boulardii was able to modulate TLR2, TLR4, MyD88, NF$\kappa \mathrm{B}$, ERK1/2, phospho-p38, phospho-JNK, TNF- $\alpha$, IL-1 $\beta$, and CXCL-1 expression, in these two different experimental models.

Based on the above studies, probiotics could be an effective therapeutic alternative for attenuating, preventing, and treating 5-FU-induced intestinal mucositis, although clinical studies will be required to test their safeness and usefulness for treatment.

\section{PREBIOTICS, SYNBIOTICS, PARAPROBIOTICS, AND POSTBIOTICS}

The use of probiotics to treat intestinal mucositis is widely reported; however, research has also demonstrated the importance of fiber consumption to improve their benefit for the intestinal microbiota. These fibers are used by the microbiota organisms during the fermentation process, resulting in the production of various compounds, such as SCFAs, which are able to modulate the function of immune cells in the intestine, showing mainly anti-inflammatory effects (Tan et al., 2014; Luu and Visekruna, 2019).

To classify dietary fibers as prebiotic, it is necessary to satisfy six basic criteria: (i) they must be resistant to gastric acidity, hydrolysis by mammalian enzymes, and gastrointestinal absorption, (ii) they should not be digested in the upper gastrointestinal tract, (iii) they should be fermented in the colon by beneficial bacteria, (iv) they should be beneficial to the host's health, (v) they should stimulate the growth of probiotics, and (vi) they should withstand food processing conditions while remaining unchanged (Wang, 2009; Markowiak and Ślizewska, 2017; Cerdó et al., 2019).

Prebiotics may be added to food or may be obtained through consumption of natural products, such as fruit, vegetables, cereals, and other edible plant products in which carbohydrate availability is high (Markowiak and Ślizewska, 2017). A wide variety of compounds have the potential to be classified as prebiotics. Most are non-digestible oligosaccharides extracted from plants, including fructooligosaccharide (FOS) (L'homme et al., 2003), galactooligosaccharide (GOS) (Ziegler et al., 2007), mannanoligosaccharide (MOS), and xylooligosaccharide
(XOS) (Playne and Crittenden, 2002), oligofructose, and inulin (Roberfroid, 2007).

Prebiotic compounds stimulate growth, activating metabolism and promoting protection of bacteria that are beneficial to the host organism (e.g., saccharolytic bacteria, Bifidobacterium, and Lactobacillus). Prebiotic fermentation by indigenous microbiota can modulate the composition and the function of these microorganisms (Gibson and Roberfroid, 1995; Slavin, 2013; Davani-Davari et al., 2019). Furthermore, prebiotic fermentation can benefit the host through production of some compounds, such as SCFAs and lactic acid, produced by Bifidobacterium and Lactobacillus spp., which cause a reduction in the intestinal $\mathrm{pH}$, inhibiting the development of gastrointestinal pathogens (Gibson and Wang, 1994; Bovee-Oudenhoven et al., 2003; Amani Denj et al., 2015). Prebiotics are also able to exert beneficial effects via mucin production by providing fermentable compounds that contribute to a lower incidence of bacterial translocation (Satchithanandam et al., 1990; Schley and Field, 2002).

Another mechanism proposed for prebiotics is their interaction with carbohydrate receptors (mannose, fucose and C-type lectin receptors, and galectins) on immune cells [phagocytes, natural killer (NK) cells, DCs]. The production of metabolites (e.g., folate and riboflavin, vitamins, and SCFAs) during their fermentation by gut microbiota showcases antimicrobial activity and maintains a healthy gut barrier (Hosono et al., 2003; Roller et al., 2004; Furusawa et al., 2013; Comstock et al., 2014; Levit et al., 2018; Enam and Mansell, 2019).

As prebiotics stimulate probiotic action, the synbiotic concept was created to overcome difficulties faced by probiotics in the GIT, demonstrating that this association (prebiotics + probiotics) intensifies their individual beneficial effects (Markowiak and Ślizewska, 2017).

Information on prebiotic stimulation of known probiotic strains leads to the choice of the ideal microorganism-substrate synbiotic pairs; the consumption of appropriately selected probiotics and prebiotics can increase the beneficial effects of each. Synbiotics have beneficial synergistic effects, greater than those observed for individual administration of prebiotics and probiotics (Geier et al., 2006).

The main criteria for synbiotic formulation should be a selection of appropriate probiotic and prebiotic pairs; the prebiotic should selectively stimulate the growth of probiotic microorganisms, having a beneficial effect on health, with no or limited stimulation of other microorganisms. The main probiotic species and prebiotics used in synbiotic formulations include, respectively, Lactobacillus spp., Bifidobacteria spp., S. boulardii, and B. coagulans, and FOS, GOS, and XOS. The health benefits from the administration of synbiotics to humans include: (i) increased levels of lactobacilli and bifidobacteria and balanced gut microbiota, (ii) improvement of immunomodulating ability, (iii) prevention of bacterial translocation; and (iv) improvement of liver function and reduction of incidence of nosocomial infections in surgical patients (Pandey et al., 2015; Markowiak and Ślizewska, 2017). Evidence shows that physical and chemical changes in the colon and intestinal microbiota caused by synbiotic 
consumption, such as increased production of SCFAs and an increase in antitumor or antimutagenic compounds, can provide protection against rectal colon cancer, as they result in an improved immune response due to changes in the microbiota (Machado et al., 2014).

The studies listed above show the advantages of using live organisms; however, despite the fact that probiotics have proven benefits for the health of the host, current research emphasizes that the living organisms are not necessary for probiotic action; their different components, such as carbohydrates, proteins, lipids, vitamins, organic acids, cell wall components, and other complex molecules, generated after cell death, also have health benefits (Cuevas-González et al., 2020). The administration of non-viable organisms and their secreted products can present advantages in safety, reducing the possibility of infection and microbial translocation, which have been reported after the administration of probiotics to immunocompromised individuals (Aguilar-Toalá et al., 2018; Cuevas-González et al., 2020).

In this context, the terms "paraprobiotics" and "postbiotics" have been defined to refer to inactivated organisms and their metabolites. The difference between them is that paraprobiotics, also known as "non-viable probiotics" refer to inactivated cells, while postbiotics refer to soluble factors, which can be products (or metabolic byproducts) secreted by viable bacteria or released after their lysis (Cuevas-González et al., 2020). It is already possible to find products on the market that contain inactivated bacteria (e.g., Lactéol Fort ${ }^{\circledR}$ from PUMC Pharmaceutical Co., Ltd. and Fermenti Lattici Tindalizzati ${ }^{\circledR}$ from Frau, AF United Spa) (Taverniti and Guglielmetti, 2011).

Microorganisms can be inactivated through ultrasound (Ojha et al., 2016), high temperatures (Chuang et al., 2007), UV radiation (Lopez et al., 2008), and other options. However, it is necessary to evaluate some details to choose the best inactivation method, as well as to evaluate the effects on microbial structure and components (Ananta and Knorr, 2009; Taverniti and Guglielmetti, 2011).

The mechanism of action of paraprobiotics is not yet fully understood, but it is known that they are capable of acting in immunomodulation (Adams, 2010). L. rhamnosus GG (LGG), inactivated by UV radiation (Lopez et al., 2008) or heat killed (Li et al., 2009), has shown interesting results. UV-inactivated LGG is as effective as living LGG in downregulating the IL-8 response in Caco- 2 cells; IL-8 is a proinflammatory chemokine released by intestinal cells (Lopez et al., 2008). Heat-killed LGG was tested in an infant rat model with LPS-induced inflammation and both live and inactivated strains administered enterally $\left(10^{8} \mathrm{CFU} / \mathrm{kg}\right)$; both were able to decrease proinflammatory mediators induced by LPS and to positively regulate anti-inflammatory mediators in the liver, plasma, and lung (Li et al., 2009).

The strains L. acidophilus A2, L. gasseri A5, and L. salivarius A6 inactivated by heat, in an in vitro experiment, were both able (at $10^{5} \mathrm{CFU} / \mathrm{ml}$ ) to stimulate splenocyte and dendritic cell proliferation and production of IL-10, IL-12-p70, and IFN$\gamma$. Likewise, L. salivarius was able to activate splenocytes and dendritic cells in mice to induce $\mathrm{T}$ cells toward a Th1 immune response. It was concluded that heat-inactivated bacteria can play an important role in modulating the immune response (Chuang et al., 2007).

A comparison was made of the in vitro potential of viable L. rhamnosus, the same bacteria inactivated by heat and the culture supernatant, for inducing the synthesis of cytokines by macrophages. Viable and heat-inactivated L. rhamnosus were able to induce the production of TNF- $\alpha$, IL- 6 , and IL-10, demonstrating a capability to exert an immunoregulatory effect on macrophages (Jorjão et al., 2015).

Postbiotics is another term that emerged after it was found that not only live probiotic bacteria are capable of promoting health benefits. Postbiotics comprise all products obtained from the metabolic processes of live bacteria or released after bacterial lysis, with biological benefits for the host (Tsilingiri and Rescigno, 2013). These products include cell surface proteins (surface-layer proteins), cell-free supernatants (CFS), cell lysates, bacteriocins, enzymes such as glutathione peroxidase (GPx) and superoxide dismutase (SOD), peptides, teichoic acids, exopolysaccharides, B-group vitamins, secreted polysaccharides, organic acids (lactate), and SCFAs (acetate, propionate, and butyrate) (Tsilingiri and Rescigno, 2013).

Postbiotic mechanisms of action have not been fully elucidated; nonetheless, there is evidence that they promote antioxidant (Xu et al., 2011; Xing et al., 2015) and antiproliferative effects (Escamilla et al., 2012; Chuah et al., 2019), stimulating antipathogenic, immunomodulatory, and anti-inflammatory proprieties (Wang et al., 2018; Gao et al., 2019).

\section{PREBIOTICS, SYNBIOTICS, AND PARAPROBIOTICS IN INTESTINAL MUCOSITIS}

A few studies describe the action of prebiotics (Figure 5A), synbiotics (Figure 5B), and paraprobiotics (Figure 5C) on intestinal mucositis. Table 1 presents the main findings of their effects in intestinal mucositis. FOS supplement (3 and 6\%) was administered to evaluate the effect on 5 -FU (150 mg/kg)induced intestinal mucositis in a murine model (Smith et al., 2008; Galdino et al., 2018). FOS was able to reduce MPO activity in a jejunum section. This was the only parameter that showed a significant reduction (Smith et al., 2008). In addition, beneficial effects of FOS (6\%) administration in an experimental model of intestinal mucositis induced by $5-\mathrm{FU}$ (300 mg/kg) were observed (Galdino et al., 2018). There was a decrease in inflammatory infiltrate, partial preservation of the intestinal epithelium, attenuation in body weight loss, and increased catalase levels, showing that supplementation with FOS could be an important adjuvant for the prevention and treatment of intestinal mucositis (Galdino et al., 2018).

Regarding the effects of synbiotics on intestinal mucositis, a commercial product called Simbioflora ${ }^{\circledR}$, which is a synbiotic compound composed of $5.5 \mathrm{~g}$ of FOS plus four probiotic strains, L. paracasei, L. rhamnosus, L. acidophilus, and B. lactis, was evaluated (Trindade et al., 2018). This synbiotic was able to attenuate weight loss, decrease intestinal permeability, 


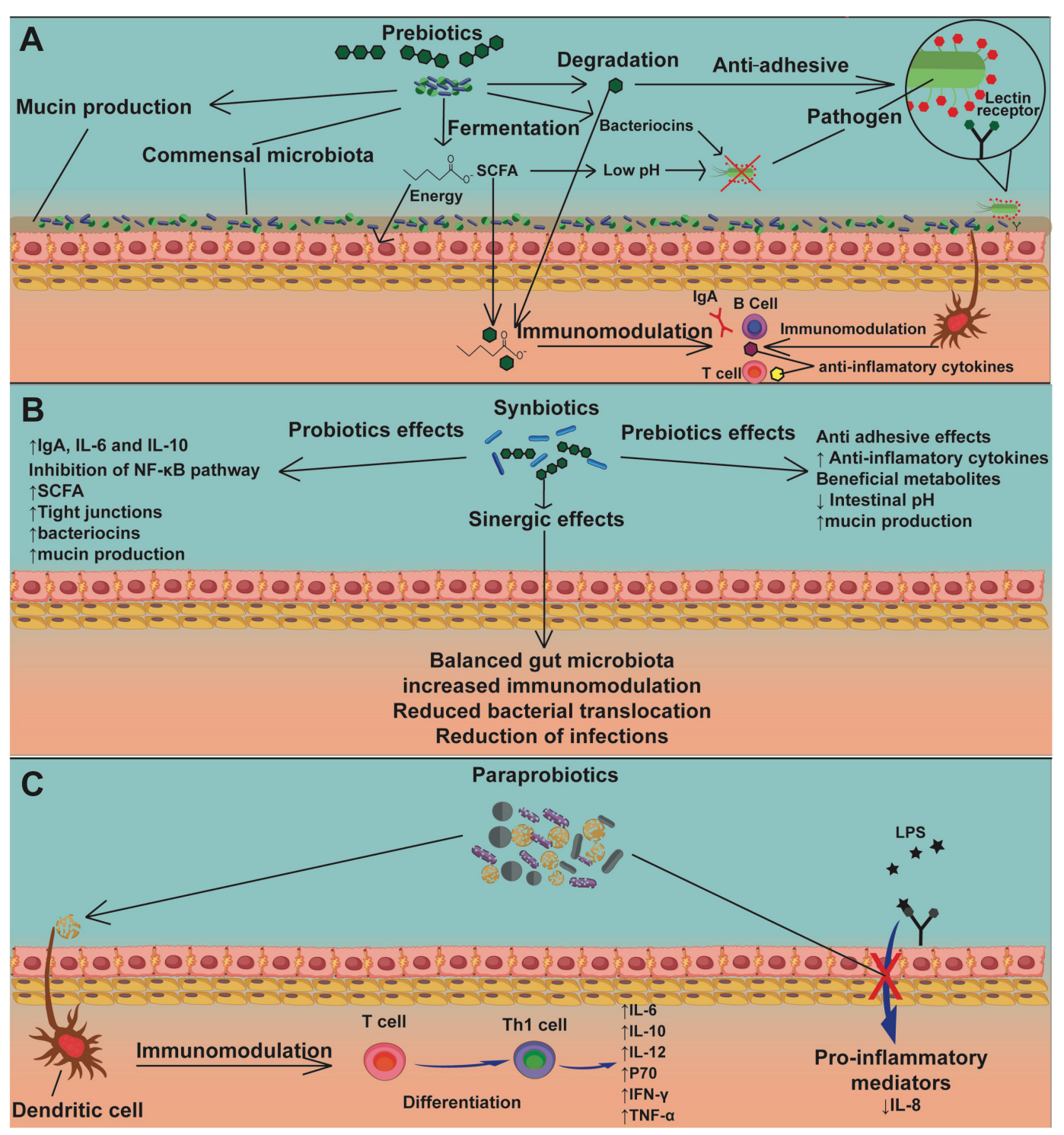

FIGURE $\mathbf{5}$ | The mechanisms of action of prebiotics, synbiotics, and paraprobiotics. Prebiotics (A) act as nourishment for beneficial bacteria in the commensal microbiota, inducing the production of mucins, SCFAs, and bacteriocins, the latter two causing pathogen inhibition. Another mechanism by which prebiotics can inhibit pathogens is by interaction with an adhesion receptor, such as the lectin receptor, demonstrating an antiadhesive action. Sub-units of prebiotics and SCFAs can be used by the host cells for energy production and promote directly or indirectly, via dendritic cells, immunomodulation of lymphocytes, stimulating production of IgA and anti-inflammatory cytokines. Synbiotics (B) have mechanisms of action of both probiotics (Figure 4) and prebiotics (A). Moreover, synbiotics have the advantage of generating a synergic effect, which promotes balance in the gut microbiota, increased immunomodulation, reduced bacterial translocation, and reduction of infections due to strong competition by probiotics against pathogens. The mechanism of action of paraprobiotics (C) is still not fully understood, though immunomodulation of T cells by dendritic cells has been reported, stimulating their differentiation into Th1 cells, promoting the production of anti-inflammatory cytokines. Another proposed mechanism is inhibition of signaling pathways related to LPS stimulation, resulting in a reduction of proinflammatory mediators, especially IL-8.

reduce eosinophil infiltrate, and also improve the histology of the intestinal mucosa, with preservation of the epithelial architecture, when compared to the administration of the isolated prebiotics (Trindade et al., 2018). In addition, it was found that this synbiotic increases the production of extracellular factors, such as SCFAs (acetate and butyrate), which could contribute to the observed immunomodulating activity (Trindade et al., 2018).
The effects of paraprobiotics on mucositis were demonstrated by Fang et al. (2014). To examine the immunomodulatory properties of $L$. rhamnosus, the bacteria were inactivated by heat and evaluated in an in vitro model of intestinal mucositis using Caco-2 cells (Fang et al., 2014). This revealed that heat does not affect the cell integrity of this bacterial species, maintaining its rod-shaped structure intact, considerably reducing the expression of monocyte 
chemoattractant protein 1 (MCP-1), and regulating the expression of TNF- $\alpha$ and IL-12. The same results were obtained with live bacteria, revealing that this bacterial species conserved intact probiotic properties after heat inactivation, making it a promising candidate for further studies (Fang et al., 2014).

In a study of the postbiotic effect on 5-FU-induced intestinal mucositis, Prisciandaro et al. (2011) found that Escherichia coli Nissle 1917 (EcN) supernatant partially protected the mouse intestine from 5-FU damage (150 mg/kg) (Prisciandaro et al., 2011). It was observed that this postbiotic was able to help avoid histological damage (villus height and crypt depth) and prevented a decrease in acidic mucin-producing goblet cells. Another study showed that oral butyrate supplementation ( $9 \mathrm{mM}$ ) was able to reduce the damage to the intestinal mucosa caused by this antineoplastic agent $(200 \mathrm{mg} / \mathrm{kg})$. Reduction in histological damage, ulceration, and amelioration in intestinal permeability were observed. The gene expression of the tight junction protein ZO-1 (zonulin) was increased, and proinflammatory cytokines, such as TNF- $\alpha$ and IL-6, were reduced (Ferreira et al., 2012).

The supernatant of mulberry leaf extract fermented by $L$. acidophilus A4 was able to reduce gene expression of proinflammatory cytokines IL-1 $\beta$ and myeloperoxidase (MPO), and stimulate overexpression of mucin genes (MUC2 and MUC5AC), thus reducing the severity of intestinal mucositis induced by 5 -FU (150 mg/kg) (Oh et al., 2017). Additionally, Lactobacillus plantarum supernatant inhibited the expression of the specific markers CD44, CD133, CD166, and ALDH1 of 5-FU-resistant colorectal cancer cells (CRC) (HT-29 and HCT116) (An and Ha, 2016). The combination therapy of this postbiotic and 5FU induced an anticancer mechanism by inactivating the Wnt/ $\beta$-catenin signaling of chemoresistant CRC cells and led to cell death by inducing caspase- 3 activity. These results suggest that probiotic secretory substances can regulate cell proliferation in colorectal cancer and may be a therapeutic alternative for treating chemoresistant colorectal cancer (An and $\mathrm{Ha}, 2016$ ).

To date, there have been few rigorous investigations examining the effect of prebiotics on 5-FU-induced intestinal mucositis. Knowing its potential in the intestinal mucosa, their supplementation with probiotics may be an attractive therapeutic alternative to ameliorate symptoms caused by mucositis, as well as other diseases involving the GIT.

Despite the significant impact of mucositis and advances in research to understand this pathology, existing therapies are mainly limited to clinical management of symptoms, aiming at electrolyte replacement, oral rehydration, and the use of adjuvant agents, such as loperamide octreotide, sucralfate enemas, sulfasalazine, and hyperbaric oxygen, to reduce fluid loss and decrease intestinal motility and diarrhea associated with mucositis, which are important debilitating symptoms (Van Sebille et al., 2015; Ribeiro et al., 2016). Given that it is necessary to find more effective therapeutic alternatives to combat intestinal mucositis, the "biotics" are strong candidates.

\section{FINAL CONSIDERATIONS}

The antineoplastic drug 5-FU is an essential and useful option for cancer treatment; however, its side effects, especially mucositis, can complicate treatment continuity and may lead to death. Effective measures to combat these symptoms, improving the quality of life of cancer patients, are crucially needed.

The probiotics have been investigated in various studies because of their beneficial properties for the GIT, including attenuation of dysbiosis. Several probiotic bacteria studied in intestinal mucositis murine models were able to attenuate and prevent intestinal histological damage, and also decrease weight loss and proinflammatory cytokine secretions, proving to be quite efficient in ameliorating the side effects to the intestine caused by 5 -FU.

Though they can improve the health of the host, administration of viable microorganisms to immunosuppressed individuals still leads to controversial clinical findings. Paraprobiotics could be an effective alternative to address this concern, since microbial cells are dead or inactivated, thus avoiding risks associated with their administration to immunocompromised individuals.

Prebiotics are also described in the literature for their regulatory ability, acting to modify the commensal microbiota to a beneficial state. However, there are a few studies evaluating their potential for helping avoid intestinal mucositis. The existing studies demonstrate that prebiotics, when associated with a probiotic, are more efficient than when they are used separately, attenuating the symptoms of mucositis and improving to almost normal status the histology of the GIT.

Therefore, probiotics, prebiotics, synbiotics, paraprobiotics, and postbiotics may be useful alternatives for the treatment of intestinal mucositis induced by 5 -FU. However, further studies are needed to elucidate all of the mechanisms of action of these bacteria and prebiotics to evolve into human clinical trials.

\section{AUTHOR CONTRIBUTIONS}

VB, TS, LT, LJ, FB, and NC-R wrote the original draft of the manuscript. VA, MD, and PM-A reviewed and revised the manuscript, obtained funding, and supervised the project. All authors contributed to the article and approved the submitted version.

\section{FUNDING}

This work was financially supported by grants from the Brazilian funding agencies, Conselho Nacional de Desenvolvimento Científico e Tecnológico (CNPq), Coordenação de Aperfeiçoamento de Pessoal de Nível Superior (CAPES), and Fundação de Amparo à Pesquisa do Estado de Minas Gerais (FAPEMIG). Centro Federal de Educação Tecnológica de Minas Gerais (CEFET/MG) and Center of Microscopy at the Universidade Federal de Minas Gerais (http://www.microscopia.ufmg.br) for providing the equipment and technical support for experiments involving electron microscopy. 


\section{REFERENCES}

Acurcio, L. B., Sandes, S. H. C., Bastos, R. W., Sant'anna, F. M., Pedroso, S. H. S. P., Reis, D. C., et al. (2017). Milk fermented by Lactobacillus species from Brazilian artisanal cheese protect germ-free-mice against Salmonella typhimurium infection. Benef. Microbes 8, 579-588. doi: 10.3920/BM20 16.0163

Adams, C. A. (2010). The probiotic paradox: Live and dead cells are biological response modifiers. Nutr. Res. Rev. 23, 37-46. doi: 10.1017/S09544224100 00090

Aguilar-Toalá, J. E., Garcia-Varela, R., Garcia, H. S., Mata-Haro, V., GonzálezCórdova, A. F., Vallejo-Cordoba, B., et al. (2018). Postbiotics: An evolving term within the functional foods field. Trends Food Sci. Technol. 75, 105-114. doi: 10.1016/j.tifs.2018.03.009

Alakomi, H.-L., Skytta, E., Saarela, M., Mattila-Sandholm, T., Latva-Kala, K., and Helander, I. M. (2000). Lactic Acid Permeabilizes Gram-Negative Bacteria by Disrupting the Outer Membrane. Appl. Environ. Microbiol. 66, 2001-2005. doi: 10.1128/AEM.66.5.2001-2005.2000

Aliakbarpour, H. R., Chamani, M., Rahimi, G., Sadeghi, A. A., and Qujeq, D. (2012). The Bacillus subtilis and Lactic Acid Bacteria Probiotics Influences Intestinal Mucin Gene Expression, Histomorphology and Growth Performance in Broilers. Asian Austr. J. Anim. Sci. 25, 1285-1293. doi: 10.5713/ajas.2012. 12110

Amani Denj, K., Razeghi Ma, M., Akrami, R., Ghobadi, S., Jafarpour, S. A., and Mirbeygi, S. K. (2015). Effect of Dietary Prebiotic Mannan Oligosaccharide (MOS) on Growth Performance, Intestinal Microflora, Body Composition, Haematological and Blood Serum Biochemical Parameters of Rainbow Trout (Oncorhynchus mykiss) Juveniles. J. Fish. Aquat. Sci. 10, 255-265. doi: 10.3923/ jfas.2015.255.265

An, J., and Ha, E.-M. (2016). Combination Therapy of Lactobacillus plantarum Supernatant and 5-Fluouracil Increases Chemosensitivity in Colorectal Cancer Cells. J. Microbiol. Biotechnol. 26, 1490-1503. doi: 10.4014/jmb.1605.05024

Ananta, E., and Knorr, D. (2009). Comparison of inactivation pathways of thermal or high pressure inactivated Lactobacillus rhamnosus ATCC 53103 by flow cytometry analysis. Food Microbiol. 26, 542-546. doi: 10.1016/j.fm.2009. 01.008

Autenrieth, D., and Baumgart, D. (2017). Mikrobiom und entzündliche Darmerkrankungen. DMW Dtsch. Medizinische Wochenschrift 142, 261-266. doi: $10.1055 / \mathrm{s}-0042-111608$

Azad, M. A. K., Sarker, M., and Wan, D. (2018). Immunomodulatory Effects of Probiotics on Cytokine Profiles. Biomed Res. Int. 2018:8063647. doi: 10.1155/ 2018/8063647

Bäckhed, F., Ley, R. E., Sonnenburg, J. L., Peterson, D. A., and Gordon, J. I. (2005). Host-bacterial mutualism in the human intestine. Science 307, 1915-1920. doi: $10.1126 /$ science. 1104816

Bastos, R. W., Pedroso, S. H. S. P., Vieira, A. T., Moreira, L. M. C., França, C. S., Cartelle, C. T., et al. (2016). Saccharomyces cerevisiae UFMG A-905 treatment reduces intestinal damage in a murine model of irinotecan-induced mucositis. Benef. Microbes 7, 549-558. doi: 10.3920/BM2015.0190

Bermudez-Brito, M., Plaza-Díaz, J., Muñoz-Quezada, S., Gómez-Llorente, C., and Gil, A. (2012). Probiotic Mechanisms of Action. Ann. Nutr. Metab. 61, 160-174. doi: $10.1159 / 000342079$

Blackwood, B. P., Yuan, C. Y., Wood, D. R., Nicolas, J. D., Grothaus, J. S., and Hunter, C. J. (2017). Probiotic Lactobacillus Species Strengthen Intestinal Barrier Function and Tight Junction Integrity in Experimental Necrotizing Enterocolitis. J. Probiotics Heal. 5:159. doi: 10.4172/2329-8901.1000159

Bovee-Oudenhoven, I. M. J., ten Bruggencate, S. J. M., Lettink-Wissink, M. L. G., and van der Meer, R. (2003). Dietary fructo-oligosaccharides and lactulose inhibit intestinal colonisation but stimulate translocation of salmonella in rats. Gut 52, 1572-1578. doi: 10.1136/gut.52.11.1572

Carvalho, R. D. D. O., do Carmo, F. L. R., de Oliveira Junior, A., Langella, P., Chatel, J.-M., Bermúdez-Humarán, L. G., et al. (2017). Use of Wild Type or Recombinant Lactic Acid Bacteria as an Alternative Treatment for Gastrointestinal Inflammatory Diseases: A Focus on Inflammatory Bowel Diseases and Mucositis. Front. Microbiol. 8:800. doi: 10.3389/fmicb.2017. 00800

Cassidy, S., and Syed, B. A. (2017). Colorectal cancer drugs market. Nat. Rev. Drug Discov. 16, 525-526. doi: 10.1038/nrd.2017.59
Castilho, N. P. A., Colombo, M., Oliveira, L. L., de Todorov, S. D., and Nero, L. A. (2019). Lactobacillus curvatus UFV-NPAC1 and other lactic acid bacteria isolated from calabresa, a fermented meat product, present high bacteriocinogenic activity against Listeria monocytogenes. BMC Microbiol. 19:63. doi: 10.1186/s12866-019-1436-1434

Cerdó, T., García-Santos, J. A., Bermúdez, M. G., and Campoy, C. (2019). The role of probiotics and prebiotics in the prevention and treatment of obesity. Nutrients 11:635. doi: 10.3390/nu11030635

Cereda, E., Caraccia, M., and Caccialanza, R. (2018). Probiotics and mucositis. Curr. Opin. Clin. Nutr. Metab. Care 21, 399-404. doi: 10.1097/MCO. 0000000000000487

Chang, C.-J., Lin, T.-L., Tsai, Y.-L., Wu, T.-R., Lai, W.-F., Lu, C.-C., et al. (2019). Next generation probiotics in disease amelioration. J. Food Drug Anal. 27, 615-622. doi: 10.1016/j.jfda.2018.12.011

Chang, C. T., Ho, T. Y., Lin, H., Liang, J. A., Huang, H. C., Li, C. C., et al. (2012). 5-fluorouracil induced intestinal mucositis via nuclear factor- $\kappa \mathrm{B}$ activation by transcriptomic analysis and in vivo bioluminescence imaging. PLoS One 7: e31808. doi: 10.1371/journal.pone.0031808

Chang, C. W., Liu, C. Y., Lee, H. C., Huang, Y. H., Li, L. H., Chiau, J. S. C., et al. (2018). Lactobacillus casei Variety rhamnosus Probiotic Preventively Attenuates 5-Fluorouracil/Oxaliplatin-Induced Intestinal Injury in a Syngeneic Colorectal Cancer Model. Front. Microbiol. 9:983. doi: 10.3389/fmicb.2018. 00983

Chuah, L.-O., Foo, H. L., Loh, T. C., Mohammed Alitheen, N. B., Yeap, S. K., Abdul Mutalib, N. E., et al. (2019). Postbiotic metabolites produced by Lactobacillus plantarum strains exert selective cytotoxicity effects on cancer cells. BMC Complement. Altern. Med. 19:114. doi: 10.1186/s12906-019-2528-2

Chuang, L., Wu, K. G., Pai, C., Hsieh, P. S., Tsai, J. J., Yen, J. H., et al. (2007). Heat-killed cells of lactobacilli skew the immune response toward T helper 1 polarization in mouse splenocytes and dendritic cell-treated T cells. J. Agric. Food Chem. 55, 11080-11086. doi: 10.1021/jf071786o

Cinausero, M., Aprile, G., Ermacora, P., Basile, D., Vitale, M. G., Fanotto, V., et al. (2017). New frontiers in the pathobiology and treatment of cancer regimenrelated mucosal injury. Front. Pharmacol. 8:354. doi: 10.3389/fphar.2017. 00354

Collado, M. C., Gueimonde, M., and Salminen, S. (2010). Probiotics in Adhesion of Pathogens. Bioact. Food Prom. Health 2010, 353-370. doi: 10.1016/B978-012-374938-3.0002322

Collins, F., Rios-Arce, N. D., Schepper, J. D., Parameswaran, N., and Mccabe, L. R. (2018). The Potential of Probiotics as a Therapy for Osteoporosis. Bugs Drugs 5, 213-233. doi: 10.1128/microbiolspec.BAD-0015-2016

Comstock, S. S., Wang, M., Hester, S. N., Li, M., and Donovan, S. M. (2014). Select human milk oligosaccharides directly modulate peripheral blood mononuclear cells isolated from 10-d-old pigs. Br. J. Nutr. 111, 819-828. doi: 10.1017/ S0007114513003267

Cordeiro, B. F., Oliveira, E. R., Da Silva, S. H., Savassi, B. M., Acurcio, L. B., Lemos, L., et al. (2018). Whey Protein Isolate-Supplemented Beverage, Fermented by Lactobacillus casei BL23 and Propionibacterium freudenreichii 138, in the Prevention of Mucositis in Mice. Front. Microbiol. 9:2035. doi: 10.3389/fmicb. 2018.02035

Crombie, J., and Longo, D. L. (2016). Principles of Cancer Treatment. Netherland: Elsevier.

Cuevas-González, P. F., Liceaga, A. M., and Aguilar-Toalá, J. E. (2020). Postbiotics and paraprobiotics: From concepts to applications. Food Res. Int. 136:109502. doi: 10.1016/j.foodres.2020.109502

Davani-Davari, D., Negahdaripour, M., Karimzadeh, I., Seifan, M., Mohkam, M., Masoumi, S., et al. (2019). Prebiotics: Definition, Types, Sources, Mechanisms, and Clinical Applications. Foods 8:92. doi: 10.3390/foods80 30092

De Jesus, L. C. L., Drumond, M. M., de Carvalho, A., Santos, S. S., Martins, F. S., Ferreira, Ê, et al. (2019). Protective effect of Lactobacillus delbrueckii subsp. Lactis CIDCA 133 in a model of 5 Fluorouracil-Induced intestinal mucositis. J. Funct. Foods 53, 197-207. doi: 10.1016/j.jff.2018.12.027

De Keersmaecker, S. C. J., Verhoeven, T. L. A., Desair, J., Marchal, K., Vanderleyden, J., and Nagy, I. (2006). Strong antimicrobial activity of Lactobacillus rhamnosus GG against Salmonella typhimurium is due to accumulation of lactic acid. FEMS Microbiol. Lett. 259, 89-96. doi: 10.1111/j.1574-6968.2006.00250.x 
de Oliveira, G. L. V., Leite, A. Z., Higuchi, B. S., Gonzaga, M. I., and Mariano, V. S. (2017). Intestinal dysbiosis and probiotic applications in autoimmune diseases. Immunology 152, 1-12. doi: 10.1111/imm.12765

Duncan, M., and Grant, G. (2003). Mucositis-Causes and Possible Treatments. Alim. Pharmacol. Ther. 18, 853-874. doi: 10.1046/j.0269-2813.2003.01784.x

Enam, F., and Mansell, T. J. (2019). Prebiotics: tools to manipulate the gut microbiome and metabolome. J. Ind. Microbiol. Biotechnol. 46, 1445-1459. doi: 10.1007/s10295-019-022032204

Escamilla, J., Lane, M. A., and Maitin, V. (2012). Cell-Free Supernatants from Probiotic Lactobacillus casei and Lactobacillus rhamnosus GG Decrease Colon Cancer Cell Invasion In Vitro. Nutr. Cancer 64, 871-878. doi: 10.1080/ 01635581.2012.700758

Fang, S., Bin Shih, H. Y., Huang, C. H., Li, L. T., Chen, C. C., and Fang, H. W. (2014). Live and heat-killed Lactobacillus rhamnosus GG upregulate gene expression of pro-inflammatory cytokines in 5-fluorouracil-pretreated Caco-2 cells. Support. Care Cancer 22, 1647-1654. doi: 10.1007/s00520-014$2137-\mathrm{z}$

FAO/WHO (2001). Joint FAO/WHO Expert Consultation on Evaluation of Health and Nutritional Properties of Probiotics. Argentina: WHO.

Fedorak, R. N., Feagan, B. G., Hotte, N., Leddin, D., Dieleman, L. A., Petrunia, D. M., et al. (2015). The probiotic VSL\#3 has anti-inflammatory effects and could reduce endoscopic recurrence after surgery for Crohn's disease. Clin. Gastroenterol. Hepatol. 13, 928-35.e2. doi: 10.1016/j.cgh.2014.10.031

Ferreira, T. M., Leonel, A. J., Melo, M. A., Santos, R. R. G., Cara, D. C., Cardoso, V. N., et al. (2012). Oral supplementation of butyrate reduces mucositis and intestinal permeability associated with 5 -fluorouracil administration. Lipids 47 , 669-678. doi: 10.1007/s11745-012-36803683

Furusawa, Y., Obata, Y., Fukuda, S., Endo, T. A., Nakato, G., Takahashi, D., et al. (2013). Commensal microbe-derived butyrate induces the differentiation of colonic regulatory T cells. Nature 504, 446-450. doi: 10.1038/nature 12721

Galdino, F. M. P., Andrade, M. E. R., de Barros, P. A. V., S. , V., Alvarez-Leite, J. I., Almeida-Leite, C. M., et al. (2018). Pretreatment and treatment with fructo-oligosaccharides attenuate intestinal mucositis induced by 5 -FU in mice. J. Funct. Foods 49, 485-492. doi: 10.1016/j.jff.2018.09.012

Gao, J., Li, Y., Wan, Y., Hu, T., Liu, L., Yang, S., et al. (2019). A Novel Postbiotic From Lactobacillus rhamnosus GG With a Beneficial Effect on Intestinal Barrier Function. Front. Microbiol. 10:477. doi: 10.3389/fmicb.2019.00477

Gao, S., Li, D., Liu, Y., Zha, E., Zhou, T., and Yue, X. (2015). Oral immunization with recombinant hepatitis $\mathrm{E}$ virus antigen displayed on the Lactococcus lactis surface enhances ORF2-specific mucosal and systemic immune responses in mice. Int. Immunopharmacol. 24, 140-145. doi: 10.1016/j.intimp.2014. 10.032

Gaspar, C., Donders, G. G., Palmeira-de-Oliveira, R., Queiroz, J. A., Tomaz, C., Martinez-de-Oliveira, J., et al. (2018). Bacteriocin production of the probiotic Lactobacillus acidophilus KS400. AMB Express 8:153. doi: 10.1186/s13568-0180679-z

Geier, M. S., Butler, R. N., and Howarth, G. S. (2006). Probiotics, prebiotics and synbiotics: a role in chemoprevention for colorectal cancer? Cancer Biol. Ther. 5, 1265-1269. doi: 10.4161/cbt.5.10.3296

Gibson, G. R., Hutkins, R., Sanders, M. E., Prescott, S. L., Reimer, R. A., Salminen, S. J., et al. (2017). Expert consensus document: The International Scientific Association for Probiotics and Prebiotics (ISAPP) consensus statement on the definition and scope of prebiotics. Nat. Rev. Gastroenterol. Hepatol. 14, 491-502. doi: $10.1038 /$ nrgastro.2017.75

Gibson, G. R., and Roberfroid, M. B. (1995). Dietary modulation of the human colonic microbiota: introducing the concept of prebiotics. J. Nutr. 125, 14011412. doi: $10.1093 / \mathrm{jn} / 125.6 .1401$

Gibson, G. R., and Wang, X. (1994). Regulatory effects of bifidobacteria on the growth of other colonic bacteria. J. Appl. Bacteriol. 77, 412-420. doi: 10.1111/j. 1365-2672.1994.tb03443.x

Gomes-Santos, A. C., Oliveira, R. P., de Moreira, T. G., Castro-Junior, A. B., Horta, B. C., Lemos, L., et al. (2017). Hsp65-Producing Lactococcus lactis Prevents Inflammatory Intestinal Disease in Mice by IL-10- and TLR2-Dependent Pathways. Front. Immunol. 8:30. doi: 10.3389/fimmu.2017.00030

Guichard, N., Guillarme, D., Bonnabry, P., and Fleury-Souverain, S. (2017). Antineoplastic drugs and their analysis: a state of the art review. Analyst 142, 2273-2321. doi: 10.1039/c7an00367f
Halder, D., Mandal, M., Chatterjee, S., Pal, N., and Mandal, S. (2017). Indigenous Probiotic Lactobacillus Isolates Presenting Antibiotic like Activity against Human Pathogenic Bacteria. Biomedicines 5:31. doi: 10.3390/ biomedicines5020031

Holleran, G., Lopetuso, L. R., Ianiro, G., Pecere, S., Pizzoferrato, M., Petito, V., et al. (2017). Gut microbiota and inflammatory bowel disease: so far so gut! Minerva Gastroenterol. Dietol 63, 373-384. doi: 10.23736/S1121-421X.17.0238 62388

Hosono, A., Ozawa, A., Kato, R., Ohnishi, Y., Nakanshi, Y., Kimura, T., et al. (2003). Dietary Fructooligosaccharides Induce Immunoregulation of Intestinal IgA Secretion by Murine Peyer's Patch Cells. Biosci. Biotechnol. Biochem. 67, 758-764. doi: 10.1271/bbb.67.758

Hsieh, M.-C., Tsai, W.-H., Jheng, Y.-P., Su, S.-L., Wang, S.-Y., Lin, C.C., et al. (2018). The beneficial effects of Lactobacillus reuteri ADR-1 or ADR-3 consumption on type 2 diabetes mellitus: a randomized, doubleblinded, placebo-controlled trial. Sci. Rep. 8:16791. doi: 10.1038/s41598-0183501435011

Jamali, J., Dayo, A., Adeel, A., Qureshi, Y., Khan, T., and Begum, S. (2018). A survey on gastrointestinal adverse drug reactions of Doxorubicin and Cyclophosphamide combination therapy. J. Pak. Med. Assoc. 68, 926-928.

Jandhyala, S. M., Talukdar, R., Subramanyam, C., Vuyyuru, H., Sasikala, M., and Reddy, D. N. (2015). Role of the normal gut microbiota. World J. Gastroenterol. 21, 8836-8847. doi: 10.3748/wjg.v21.i29.8787

Jorjão, A. L., De Oliveira, F. E., Vieira, M., Leão, P., Antonio, C., Carvalho, T., et al. (2015). ATCC 7469 May Induce Modulatory Cytokines Profiles on Macrophages RAW 264. Scien. World J. 2015:716749.

Justino, P. F. C., Franco, A. X., Pontier-Bres, R., Monteiro, C. E. S., Barbosa, A. L. R., Souza, M. H. L. P., et al. (2020). Modulation of 5-fluorouracil activation of tolllike/MyD88/NF-кB/MAPK pathway by Saccharomyces boulardii CNCM I-745 probiotic. Cytokine 125:154791. doi: 10.1016/j.cyto.2019.154791

Justino, P. F. C., Melo, L. F. M., Nogueira, A. F., Morais, C. M., Mendes, W. O., Franco, A. X., et al. (2015). Regulatory role of Lactobacillus acidophilus on inflammation and gastric dysmotility in intestinal mucositis induced by 5 fluorouracil in mice. Cancer Chemother. Pharmacol. 75, 559-567. doi: 10.1007/ s00280-014-2663-x

Kaci, G., Lakhdari, O., Doré, J., Ehrlich, S. D., Renault, P., Blottière, H. M., et al. (2011). Inhibition of the NF-кB Pathway in Human Intestinal Epithelial Cells by Commensal Streptococcus salivarius. Appl. Environ. Microbiol. 77, 4681-4684. doi: 10.1128/AEM.030213010

Kato, S., Hamouda, N., Kano, Y., Oikawa, Y., Tanaka, Y., Matsumoto, K., et al. (2017). Probiotic Bifidobacterium bifidum G9-1 attenuates 5-fluorouracilinduced intestinal mucositis in mice via suppression of dysbiosis-related secondary inflammatory responses. Clin. Exp. Pharmacol. Physiol. 44, 10171025. doi: 10.1111/1440-1681.12792

Kim, H. J., Kim, J. H., Moon, W., Park, J., Park, S. J., Song, G. A., et al. (2015). Rebamipide Attenuates 5-Fluorouracil-Induced Small Intestinal Mucositis in a Mouse Model. Biol. Pharm. Bull. 38, 179-183. doi: 10.1248/bpb.b1400400

Kim, N., Yun, M., Oh, Y. J., and Choi, H.-J. (2018). Mind-altering with the gut: Modulation of the gut-brain axis with probiotics. J. Microbiol. 56, 172-182. doi: 10.1007/s12275-018-80328034

Kim, S., Chun, H., Choi, H., Kim, E., Keum, B., Seo, Y., et al. (2018). Ursodeoxycholic acid attenuates 5-fluorouracil-induced mucositis in a rat model. Oncol. Lett. 16, 2585-2590. doi: 10.3892/ol.2018.8893

König, J., Wells, J., Cani, P. D., García-Ródenas, C. L., MacDonald, T., Mercenier, A., et al. (2016). Human intestinal barrier function in health and disease. Clin. Transl. Gastroenterol 7:e196 doi: 10.1038/ctg.2016.54

Kuczkowska, K., Øverland, L., Rocha, S. D. C., Eijsink, V. G. H., and Mathiesen, G. (2019). Comparison of eight Lactobacillus species for delivery of surfacedisplayed mycobacterial antigen. Vaccine 37, 6371-6379. doi: 10.1016/j.vaccine. 2019.09.012

Lane, E. R., Zisman, T. L., and Suskind, D. L. (2017). The microbiota in inflammatory bowel disease: Current and therapeutic insights. J. Inflamm. Res. 10, 63-73. doi: 10.2147/JIR.S116088

LeCureux, J. S., and Dean, G. A. (2018). Lactobacillus Mucosal Vaccine Vectors: Immune Responses against Bacterial and Viral Antigens. mSphere 3, e0061-18. doi: $10.1128 / \mathrm{mSphere} .00061-18$ 
Lee, C. S. (2014). Gastro-intestinal toxicity of chemotherapeutics in colorectal cancer: The role of inflammation. World J. Gastroenterol. 20:3751-3761. doi: 10.3748/wjg.v20.i14.3751

Levit, R., Savoy de Giori, G., de Moreno, de LeBlanc, A., and LeBlanc, J. G. (2018). Protective effect of the riboflavin-overproducing strain Lactobacillus plantarum CRL2130 on intestinal mucositis in mice. Nutrition 54, 165-172. doi: 10.1016/j.nut.2018.03.056

L'homme, C., Arbelot, M., Puigserver, A., and Biagini, A. (2003). Kinetics of Hydrolysis of Fructooligosaccharides in Mineral-Buffered Aqueous Solutions: Influence of $\mathrm{pH}$ and Temperature. J. Agric. Food Chem. 51, 224-228. doi: 10.1021/jf0204699

Li, N., Russell, W. M., Douglas-Escobar, M., Hauser, N., Lopez, M., and Neu, J. (2009). Live and heat-killed lactobacillus rhamnosus GG: Effects on proinflammatory and anti-inflammatory cytokines/chemokines in gastrostomy-fed infant rats. Pediatr. Res. 66, 203-207. doi: 10.1203/PDR. 0b013e3181aabd4f

Longley, D. B., Harkin, D. P., and Johnston, P. G. (2003). 5-Fluorouracil: Mechanisms of action and clinical strategies. Nat. Rev. Cancer 3, 330-338. doi: $10.1038 / \mathrm{nrc1074}$

Lopez, M., Li, N., Kataria, J., Russell, M., and Neu, J. (2008). Live and Ultraviolet-Inactivated Lactobacillus Rhamnosus GG Decrease FlagellinInduced Interleukin-8 Production in Caco-2 Cells. J. Nutr. 138, 2264-2268. doi: $10.3945 /$ jn. 108.093658

Luu, M., and Visekruna, A. (2019). Short-chain fatty acids: Bacterial messengers modulating the immunometabolism of T cells. Eur. J. Immunol. 49, 842-848. doi: 10.1002/eji.201848009

Machado, F. F., Lazzaretti, R. K., and Poziomyck, A. K. (2014). Uso de Prebióticos, Probióticos e Simbióticos nos Pré e Pós- -Operatórios do Câncer Colorretal: uma Revisão. Rev. Bras. Cancerol. 60, 363-370.

Makras, L., Triantafyllou, V., Fayol-Messaoudi, D., Adriany, T., Zoumpopoulou, G., Tsakalidou, E., et al. (2006). Kinetic analysis of the antibacterial activity of probiotic lactobacilli towards Salmonella enterica serovar Typhimurium reveals a role for lactic acid and other inhibitory compounds. Res. Microbiol. 157, 241-247. doi: 10.1016/j.resmic.2005.09.002

Markowiak, P., and Ślizewska, K. (2017). Effects of probiotics, prebiotics, and synbiotics on human health. Nutrients 9:1021. doi: 10.3390/nu9091021

Martins, C. C., and Wagner, S. C. (2013). Individualização Farmacocinética das Doses de 5-Fluoruracil no Câncer Colorretal. Rev. Bras. Cancerol. 59, 271-280.

Mathur, S., and Singh, R. (2005). Antibiotic resistance in food lactic acid bacteriaa review. Int. J. Food Microbiol. 105, 281-295. doi: 10.1016/j.ijfoodmicro.2005. 03.008

Mi, H., Dong, Y., Zhang, B., Wang, H., Peter, C. C. K., Gao, P., et al. (2017). Bifidobacterium Infantis Ameliorates Chemotherapy-Induced Intestinal Mucositis Via Regulating T Cell Immunity in Colorectal Cancer Rats. Cell. Physiol. Biochem. 42, 2330-2341. doi: 10.1159/000480005

Miura, K., Kinouchi, M., Ishida, K., Fujibuchi, W., Naitoh, T., Ogawa, H., et al. (2010). 5-FU Metabolism in Cancer and Orally-Administrable 5-FU Drugs. Cancers 2, 1717-1730. doi: 10.3390/cancers2031717

Mokoena, M. P. (2017). Lactic Acid Bacteria and Their Bacteriocins: Classification, Biosynthesis and Applications against Uropathogens: A Mini-Review. Molecules 22:1255. doi: 10.3390/molecules22081255

Monteagudo-Mera, A., Rastall, R. A., Gibson, G. R., Charalampopoulos, D., and Chatzifragkou, A. (2019). Adhesion mechanisms mediated by probiotics and prebiotics and their potential impact on human health. Appl. Microbiol. Biotechnol. 103, 6463-6472. doi: 10.1007/s00253-019-099789977

Mowat, A. M., and Agace, W. W. (2014). Regional specialization within the intestinal immune system. Nat. Rev. Immunol. 14, 667-685. doi: 10.1038/ nri3738

Nussbaumer, S., Bonnabry, P., Veuthey, J.-L., and Fleury-Souverain, S. (2011). Analysis of anticancer drugs: A review. Talanta 85, 2265-2289. doi: 10.1016/ j.talanta.2011.08.034

Oh, N. S., Lee, J. Y., Lee, J. M., Lee, K. W., and Kim, Y. (2017). Mulberry leaf extract fermented with Lactobacillus acidophilus A4 ameliorates 5-fluorouracilinduced intestinal mucositis in rats. Lett. Appl. Microbiol. 64, 459-468. doi: 10.1111/lam.12741

Ojha, K. S., Kerry, J. P., Alvarez, C., Walsh, D., and Tiwari, B. K. (2016). Effect of high intensity ultrasound on the fermentation profile of Lactobacillus sakei in a meat model system. Ultrason. Sonochem. 31, 539-545. doi: 10.1016/j.ultsonch. 2016.01.001

Pandey, K. R., Naik, S. R., and Vakil, B. V. (2015). Probiotics, prebiotics and synbiotics- a review. J. Food Sci. Technol. 52, 7577-7587. doi: 10.1007/s13197015-19211921

Parada Venegas, D., De la Fuente, M. K., Landskron, G., González, M. J., Quera, R., Dijkstra, G., et al. (2019). Short Chain Fatty Acids (SCFAs)-Mediated Gut Epithelial and Immune Regulation and Its Relevance for Inflammatory Bowel Diseases. Front. Immunol 10:277. doi: 10.3389/fimmu.2019. 00277

Plavec, T. V., and Berlec, A. (2019). Engineering of lactic acid bacteria for delivery of therapeutic proteins and peptides. Appl. Microbiol. Biotechnol. 103, 20532066. doi: 10.1007/s00253-019-09628-y

Playne, R., and Crittenden, M. (2002). Purification of food-grade oligosaccharides using immobilised cells of Zymomonas mobilis. Appl. Microbiol. Biotechnol. 58, 297-302. doi: 10.1007/s00253-001-0886883

Plaza-Díaz, J., Ruiz-Ojeda, F., Vilchez-Padial, L., and Gil, A. (2017). Evidence of the Anti-Inflammatory Effects of Probiotics and Synbiotics in Intestinal Chronic Diseases. Nutrients 9:555. doi: 10.3390/nu9060555

Porto, B. A. A., Monteiro, C. F., Souza, ÉL. S., Leocádio, P. C. L., AlvarezLeite, J. I, Generoso, S. V., et al. (2019). Treatment with selenium-enriched Saccharomyces cerevisiae UFMG A-905 partially ameliorates mucositis induced by 5-fluorouracil in mice. Cancer Chemother. Pharmacol. 84, 117-126. doi: 10.1007/s00280-019-038653868

Pot, B., Foligné, B., Daniel, C., and Grangette, C. (2013). Understanding immunomodulatory effects of probiotics. Nestle Nutr. Inst. Workshop Ser. 77, 75-90. doi: 10.1159/000351388

Prisciandaro, L. D., Geier, M. S., Butler, R. N., Cummins, A. G., and Howarth, G. S. (2011). Probiotic factors partially improve parameters of 5-fluorouracilinduced intestinal mucositis in rats. Cancer Biol. Ther. 11, 671-677. doi: 10. 4161/cbt.11.7.14896

Quaresma, M., Damasceno, S., Monteiro, C., Lima, F., Mendes, T., Lima, M., et al. (2019). Probiotic mixture containing Lactobacillus spp. and Bifidobacterium spp. attenuates 5-fluorouracil-induced intestinal mucositis in mice. Nutr. Cancer 12, 1-11. doi: 10.1080/01635581.2019.1675719

Rad, A. H., Aghebati-Maleki, L., Kafil, H. S., and Abbasi, A. (2020). Molecular mechanisms of postbiotics in colorectal cancer prevention and treatment. Crit. Rev. Food Sci. Nutr. 15, 1-17. doi: 10.1080/10408398.2020.17 65310

Rajilić-Stojanović, M., and de Vos, W. M. (2014). The first 1000 cultured species of the human gastrointestinal microbiota. FEMS Microbiol. Rev. 38, 996-1047. doi: 10.1111/1574-6976.12075

Rather, I. A., Bajpai, V. K., Kumar, S., Lim, J., Paek, W. K., and Park, Y.-H. (2016). Probiotics and Atopic Dermatitis: An Overview. Front. Microbiol. 7:507. doi: $10.3389 /$ fmicb.2016.00507

Ribeiro, R. A., Wanderley, C. W. S., Wong, D. V. T., Mota, J. M. S. C., Leite, C. A. V. G., Souza, M. H. L. P., et al. (2016). Irinotecan- and 5-fluorouracil-induced intestinal mucositis: insights into pathogenesis and therapeutic perspectives. Cancer Chemother. Pharmacol. 78, 881-893. doi: 10. 1007/s00280-016-3139-y

Roberfroid, M. B. (2007). Inulin-Type Fructans: Functional Food Ingredients. J. Nutr 137, 2493S-2502S. doi: 10.1093/jn/137.11.2493S

Roller, M., Rechkemmer, G., and Watzl, B. (2004). Prebiotic Inulin Enriched with Oligofructose in Combination with the Probiotics Lactobacillus rhamnosus and Bifidobacterium lactis Modulates Intestinal Immune Functions in Rats. J. Nutr. 134, 153-156. doi: 10.1093/jn/134.1.153

Saez-Lara, M. J., Gomez-Llorente, C., Plaza-Diaz, J., and Gil, A. (2015). The role of probiotic lactic acid bacteria and bifidobacteria in the prevention and treatment of inflammatory bowel disease and other related diseases: A systematic review of randomized human clinical trials. Biomed Res. Int. 2015:505878. doi: 10.1155/ $2015 / 505878$

Salvo Romero, E., Alonso Cotoner, C., Pardo Camacho, C., Casado Bedmar, M., and Vicario, M. (2015). The intestinal barrier function and its involvement in digestive disease. Rev. Española Enfermedades Dig. 108, 686-695. doi: 10.17235/ reed.2015.3846/2015

Satchithanandam, S., Vargofcak-Apker, M., Calvert, R. J., Leeds, A. R., and Cassidy, M. M. (1990). Alteration of Gastrointestinal Mucin by Fiber Feeding in Rats. J. Nutr. 120, 1179-1184. doi: 10.1093/jn/120.10.1179 
Schley, P. D., and Field, C. J. (2002). The immune-enhancing effects of dietary fibres and prebiotics. Br. J. Nutr. 87, S221-S230. doi: 10.1079/bjn/20 02541

Shi, Y., Zhai, Q., Li, D., Mao, B., Liu, X., Zhao, J., et al. (2017). Restoration of cefixime-induced gut microbiota changes by Lactobacillus cocktails and fructooligosaccharides in a mouse model. Microbiol. Res. 200, 14-24. doi: 10. 1016/j.micres.2017.04.001

Shields, M. (2017). Chemotherapeutics. In Pharmacognosy: Fundamentals, Applications and Strategy. Netherland: Elsevier Inc, 295-313.

Simon, G. L., and Gorbach, S. L. (1982). Intestinal Microflora. Med. Clin. North Am. 66, 557-574. doi: 10.1016/S0025-7125(16)31407-9

Slavin, J. (2013). Fiber and prebiotics: mechanisms and health benefits. Nutrients 5 , 1417-1435. doi: 10.3390/nu5041417

Smith, C. L., Geier, M. S., Yazbeck, R., Torres, D. M., Butler, R. N., and Howarth, G. S. (2008). Lactobacillus fermentum BR11 and fructooligosaccharide partially reduce jejunal inflammation in a model of intestinal mucositis in rats. Nutr. Cancer 60, 757-767. doi: 10.1080/016355808021 92841

Soccol, C. R., Vandenberghe, L. P., de, S., Spier, M. R., Medeiros, A. B. P., Yamaguishi, C. T., et al. (2010). The potential of probiotics: A review. Food Technol. Biotechnol. 48, 413-434.

Sonis, S. T. (2004). The pathobiology of mucositis. Nat. Rev. Cancer 4, 277-284. doi: $10.1038 / \mathrm{nrc1} 1318$

Soveri, L. M., Hermunen, K., De Gramont, A., Poussa, T., Quinaux, E., Bono, P., et al. (2014). Association of adverse events and survival in colorectal cancer patients treated with adjuvant 5-fluorouracil and leucovorin: Is efficacy an impact of toxicity? Eur. J. Cancer 50, 2966-2974. doi: 10.1016/j.ejca.2014. 08.017

Stringer, A. M., Gibson, R. J., Logan, R. M., Bowen, J. M., Yeoh, A. S. J., Hamilton, J., et al. (2009). Gastrointestinal Microflora and Mucins May Play a Critical Role in the Development of 5-Fluorouracil-Induced Gastrointestinal Mucositis. Exp. Biol. Med. 234, 430-441. doi: 10.3181/0810-RM-301

Tan, J., McKenzie, C., Potamitis, M., Thorburn, A. N., Mackay, C. R., and Macia, L. (2014). The role of short-chain fatty acids in health and disease. Adv. Immunol. 121, 91-119. doi: 10.1016/B978-0-12-800100-4.000039

Tang, Y., Wu, Y., Huang, Z., Dong, W., Deng, Y., Wang, F., et al. (2017). Administration of probiotic mixture DM\#1 ameliorated 5-fluorouracil-induced intestinal mucositis and dysbiosis in rats. Nutrition. 33, 96-104. doi: 10.1016/j. nut.2016.05.003

Taverniti, V., and Guglielmetti, S. (2011). The immunomodulatory properties of probiotic microorganisms beyond their viability (ghost probiotics: Proposal of paraprobiotic concept). Genes Nutr. 6, 261-274. doi: 10.1007/s12263-0110218-x

Thomas, S. A., Grami, Z., Mehta, S., Patel, K., North, W., and Hospital, F. (2016). Adverse Effects of 5-fluorouracil: Focus on Rare Side Effects. Cancer Cell Microenviron. 3, 3-6. doi: $10.14800 / \mathrm{ccm} .1266$

Thursby, E., and Juge, N. (2017). Introduction to the human gut microbiota. Biochem. J. 474, 1823-1836. doi: 10.1042/BCJ20160510

Touchefeu, Y., Montassier, E., Nieman, K., Gastinne, T., Potel, G., Bruley Des, et al. (2014). Systematic review: The role of the gut microbiota in chemotherapy- or radiation-induced gastrointestinal mucositis - Current evidence and potential clinical applications. Aliment. Pharmacol. Ther. 40, 409-421. doi: 10.1111/apt. 12878

Trindade, L. M., Martins, V. D., Rodrigues, N. M., Souza, E. L. S., Martins, F. S., Costa, G. M. F., et al. (2018). Oral administration of Simbioflora ${ }^{\circledR}$ (synbiotic) attenuates intestinal damage in a mouse model of 5fluorouracil-induced mucositis. Benef. Microbes 9, 477-486. doi: 10.3920/BM20 17.0082

Tsilingiri, K., and Rescigno, M. (2013). Postbiotics: what else? Benef. Microbes 4, 101-107. doi: 10.3920/BM2012.0046

van Reenen, C. A., and Dicks, L. M. T. (2011). Horizontal gene transfer amongst probiotic lactic acid bacteria and other intestinal microbiota: what are the possibilities? A review. Arch. Microbiol. 193, 157-168. doi: 10.1007/s00203-0100668663

Van Sebille, Y. Z. A., Stansborough, R., Wardill, H. R., Bateman, E., Gibson, R. J., and Keefe, D. M. (2015). Management of Mucositis During Chemotherapy: From Pathophysiology to Pragmatic Therapeutics. Curr. Oncol. Rep. 17:50. doi: 10.1007/s11912-015-0474479 van Vliet, M. J., Harmsen, H. J. M., de Bont, E. S. J. M., and Tissing, W. J. E. (2010). The Role of Intestinal Microbiota in the Development and Severity of Chemotherapy-Induced Mucositis. PLoS Pathog. 6:e1000879. doi: 10.1371/ journal.ppat.1000879

Vancamelbeke, M., and Vermeire, S. (2017). The intestinal barrier: a fundamental role in health and disease. Expert Rev. Gastroenterol. Hepatol. 11, 821-834. doi: $10.1080 / 17474124.2017 .1343143$

Villa, A., and Sonis, S. T. (2015). Mucositis: Pathobiology and management. Curr. Opin. Oncol. 27, 159-164. doi: 10.1097/CCO.00000000000 00180

von Bültzingslöwen, I., Adlerberth, I., Wold, A. E., Dahlén, G., and Jontell, M. (2003). Oral and intestinal microflora in 5-fluorouracil treated rats, translocation to cervical and mesenteric lymph nodes and effects of probiotic bacteria. Oral Microbiol. Immunol. 18, 278-284. doi: 10.1034/j.1399-302x.2003. 00075.x

Wallace, C. J. K., Foster, J. A., Soares, C. N., and Milev, R. V. (2020). The Effects of Probiotics on Symptoms of Depression: Protocol for a Double-Blind Randomized Placebo-Controlled Trial. Neuropsychobiology 79, 108-116. doi: $10.1159 / 000496406$

Walter, J., and Ley, R. (2011). The Human Gut Microbiome: Ecology and Recent Evolutionary Changes. Annu. Rev. Microbiol. 65, 411-429. doi: 10.1146/ annurev-micro-090110102830

Wang, G., Li, X., Zhao, J., Zhang, H., and Chen, W. (2017). Lactobacillus casei CCFM419 attenuates type 2 diabetes via a gut microbiota dependent mechanism. Food Funct. 8, 3155-3164. doi: 10.1039/C7FO00593H

Wang, H., Zhang, L., Xu, S., Pan, J., Zhang, Q., and Lu, R. (2018). Surface-Layer Protein from Lactobacillus acidophilus NCFM Inhibits LipopolysaccharideInduced Inflammation through MAPK and NF- $\mathrm{BB}$ Signaling Pathways in RAW264.7 Cells. J. Agric. Food Chem. 66, 7655-7662. doi: 10.1021/acs.jafc. $8 \mathrm{~b} 02012$

Wang, M., Gao, Z., Zhang, Y., and Pan, L. (2016). Lactic acid bacteria as mucosal delivery vehicles: a realistic therapeutic option. Appl. Microbiol. Biotechnol. 100, 5691-5701. doi: 10.1007/s00253-016-7557-x

Wang, Y., George, S. P., Roy, S., Pham, E., Esmaeilniakooshkghazi, A., and Khurana, S. (2016). Both the anti-and pro-apoptotic functions of villin regulate cell turnover and intestinal homeostasis. Sci. Rep. 6, 1-10. doi: 10.1038/ srep35491

Wang, Y. (2009). Prebiotics: Present and future in food science and technology. Food Res. Int. 42, 8-12. doi: 10.1016/j.foodres.2008.09.001

World Health Organization [WHO] (2018). No Title. Fact sheets-Cancer. Switzerland: WHO.

Wu, Y., Wang, B., Xu, H., Tang, L., Li, Y., Gong, L., et al. (2019). Probiotic Bacillus Attenuates Oxidative Stress- Induced Intestinal Injury via p38Mediated Autophagy. Front. Microbiol. 10:2185. doi: 10.3389/fmicb.2019. 02185

Xing, J., Wang, G., Zhang, Q., Liu, X., Gu, Z., Zhang, H., et al. (2015). Determining Antioxidant Activities of Lactobacilli Cell-Free Supernatants by Cellular Antioxidant Assay: A Comparison with Traditional Methods. PLoS One 10:e0119058. doi: 10.1371/journal.pone.0119058

$\mathrm{Xu}, \mathrm{R}$., Shang, N., and Li, P. (2011). In vitro and in vivo antioxidant activity of exopolysaccharide fractions from Bifidobacterium animalis RH. Anaerobe 17, 226-231. doi: 10.1016/j.anaerobe.2011.07.010

Yeung, C. Y., Chan, W. T., Jiang, C., Bin, Cheng, M. L., Liu, C. Y., et al. (2015). Amelioration of chemotherapy-induced intestinal mucositis by orally administered probiotics in a mouse model. PLoS One 10:1-16. doi: 10.1371/ journal.pone. 0138746

Yu, J. (2013). Intestinal stem cell injury and protection during cancer therapy. Transl. Cancer Res. 2, 384-396. doi: 10.3978/j.issn.2218-676X.2013. 07.03

Yu, L. C. H. (2018). Microbiota dysbiosis and barrier dysfunction in inflammatory bowel disease and colorectal cancers: exploring a common ground hypothesis. J. Biomed. Sci. 25:79. doi: 10.1186/s12929-018-0483-8

Zaharuddin, L., Mokhtar, N. M., Muhammad Nawawi, K. N., and Raja Ali, R. A. (2019). A randomized double-blind placebo-controlled trial of probiotics in post-surgical colorectal cancer. BMC Gastroenterol. 19:131. doi: 10.1186/ s12876-019-10471044

Zhang, F., Gao, J., Wang, B., Huo, D., Wang, Z., Zhang, J., et al. (2018). Wholegenome sequencing reveals the mechanisms for evolution of streptomycin 
resistance in Lactobacillus plantarum. J. Dairy Sci. 101, 2867-2874. doi: 10. 3168/jds.201713323

Zhang, N., Yin, Y., Xu, S. J., and Chen, W. S. (2008). 5-Fluorouracil: Mechanisms of resistance and reversal strategies. Molecules 13, 1551-1569. doi: 10.3390/ molecules 13081551

Ziegler, E., Vanderhoof, J. A., Petschow, B., Mitmesser, S. H., Stolz, S. I., Harris, C. L., et al. (2007). Term Infants Fed Formula Supplemented With Selected Blends of Prebiotics Grow Normally and Have Soft Stools Similar to Those Reported for Breast-fed Infants. J. Pediatr. Gastroenterol. Nutr. 44, 359-364. doi: 10.1097/MPG.0b013e3180 $2 \mathrm{fca} 8 \mathrm{c}$
Conflict of Interest: The authors declare that the research was conducted in the absence of any commercial or financial relationships that could be construed as a potential conflict of interest.

Copyright (c) 2020 Batista, da Silva, de Jesus, Coelho-Rocha, Barroso, Tavares, Azevedo, Mancha-Agresti and Drumond. This is an open-access article distributed under the terms of the Creative Commons Attribution License (CC BY). The use, distribution or reproduction in other forums is permitted, provided the original author(s) and the copyright owner(s) are credited and that the original publication in this journal is cited, in accordance with accepted academic practice. No use, distribution or reproduction is permitted which does not comply with these terms. 